${ }_{4} \quad$ Nouredine Tamani*1, Patricio Mosse ${ }^{2}$, Madalina Croitoru ${ }^{1}$,

$5 \quad$ Patrice Buche ${ }^{1,2}$, Valérie Guillard ${ }^{2}$, Carole Guillaume ${ }^{2}$, and

6

9

10

11

\section{An Argumentation System for Eco-Efficient Packaging Material Selection}

\author{
Nathalie Gontard ${ }^{2}$ \\ ${ }^{1}$ INRIA Graphik LIRMM 161 rue Ada Montpellier, France \\ tamani@lirmm.fr, ntamani@gmail.com,croitoru@lirmm.fr \\ *Corresponding author. Tel. +33467418 662 . \\ ${ }^{2}$ UMR IATE INRA UM2 2 place Pierre Viala Montpellier, France. \\ patricio.mosse@gmail.com, patrice.buche@supagro.inra.fr, \{guillard, Guillaume, \\ Gontard\}@um2.fr
}




\begin{abstract}
Within the framework of the European project EcoBioCap (ECOefficient BIOdegradable Composite Advanced Packaging), aiming at conceiving the next generation of food packagings, we have designed an argumentation-based tool for management of conflicting viewpoints between preferences expressed by the involved parties (food and packaging industries, health authorities, consumers, waste management authority, etc.). The requirements and user preferences are modeled by several rules provided by the stakeholders expressing their viewpoints and expertise. Based on these rules, the argumentation tool computes consensual preferences which are used to parametrize a flexible querying process of a packaging database to retrieve the most relevant solution to pack a given food. In this paper, we recall briefly the principles underlying the reasoning process, and we detail the main functionalities and the architecture of the argumentation tool. We cover the overall reasoning steps starting from formal representation of text arguments and ending by extraction of justified preferences which are sent to the database querying process. Finally, we detail its operational functioning through a real life case study to determine the justifiable choices between recyclable, compostable and biodegradable packaging materials based on stakeholders' arguments.
\end{abstract}


Keywords. Logic-based argumentation, argumentation tool, decision support system, Food packaging.

\section{Introduction}

Within the framework of the European project EcoBioCap (ECOefficient BIOdegradable Composite Advanced Packaging), we have designed a Decision Support System (called DSS) whose objective is to select, for a given food, the most relevant packaging materials according to possibly conflicting requirements (food to pack, shelf life, storage temperature, packaging biodegradability, etc.) expressed by the involved parties (food and packaging industries, health authorities, consumers, waste management authority, etc.).

The DSS software, as depicted in Figure 1, realizes a multi-criteria flexible querying process [Destercke et al., 2011] which takes as inputs desired preferences associated with packaging characteristics (dimensions, minimum shelf life, biodegradability, transparency, ...) and uses them to query a packaging database to retrieve a ranked list of most relevant packagings. Optimal permeabilities of the targeted packaging can be computed thanks to a Modified Atmosphere Packaging (MAP) simulation model [Guillard et al., 2012]. In this paper, we propose a new component of the DSS. It implements an argumentation process which aims at combining several stakeholders (researchers, consumers, food industry, packaging industry, waste management 
policy, etc.) requirements expressed as simple textual arguments, to enrich the querying process by stakeholders' justified preferences. Each argument supports/opposes a choice justified by the fact that it either meets or does not meet a requirement according to a particular aspect of the packagings (end of life management, transparency, ...).

For example, a market shop manager expresses the need for a new packaging to pack apricots such that its dimensions are $20 \mathrm{~cm}$ in length, $15 \mathrm{~cm}$ in width and $15 \mathrm{~cm}$ in depth and ensures a minimum shelf life of 10 days. The design of this new packaging needs also to take into consideration the packaging industry constraints (ability to scale-up the production process, the availability of the row material, etc.), the waste management administration rules about packaging end of life (biodegradability, recyclability, incineration, burying, etc.) and consumer preferences (transparent packaging, environment-friendly packaging, no extra-cost due to packaging, etc.).

As illustrated in Figure 1, the former conditions (dimensions and shelf life in addition to the fresh food to pack, i.e. apricots in this case) are the inputs of the virtual MAP simulator which returns the optimal parameters for gaz (O2 and CO2) permeability to ensure the shelf life required to preserve the apricots. The latter conditions are expressed as text arguments of the form "Biodegradable materials are suitable since they help to protect the environment" or "Life cycle analysis results are not in favor of biodegradable and compostable materials". These arguments are the input of the argumentation system which distinguishes for each option (biodegradable material, 


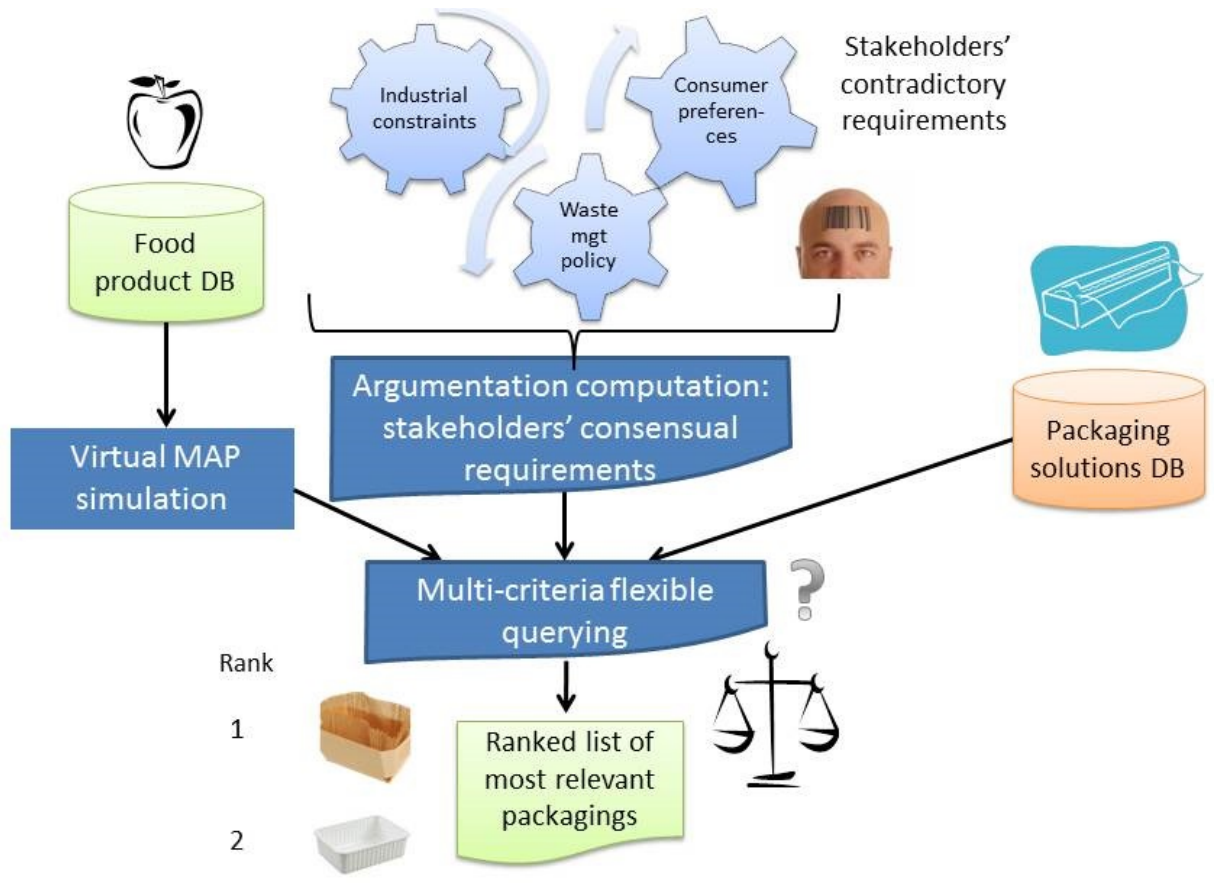

Figure 1: Global insight of the DSS.

78

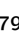

compostable material, etc.) the reason leading to its acceptance or its rejection. Then, the argumentation system detects the conflicts among the arguments and computes the sets of coherent arguments which defend themselves against attacks. After that, it extracts from the winner arguments the most justified options (for instance biodegradable materials) as predicates in order to enrich the querying process. Finally, the multi-criteria flexible querying system combines the outputs of both virtual MAP system and argumentation system to deliver from the Packaging Solution DB the list of packaging materials satisfying the requirements.

We detail in this paper how arguments are modeled within a structured 
argumentation system and how the delivered justified conclusions can be used in the querying process. This paper is a detailed and an extended version of the previous work [Tamani et al., 2014].

Thus, packagings have to be selected according to several aspects or criteria (permeance, interaction with the packed food, end of life, etc.) highlighted by arguments expressed by the stakeholders involved in the project. The problem at hand does not simply consist in addressing a multi-criteria optimization problem [Bouyssou et al., 2009], but the DSS would need to be able to justify why certain packagings are chosen. To this aim, we make use of argumentation theory [Dung, 1995, Besnard and Hunter, 2008, Rahwan and Simari, 2009], in which some approaches combine argumentation and multi criteria decision making [Amgoud and Prade, 2009].

The arguments we consider in this paper are based on a defeasible reasoning. We rely in this work on a logical-based structured argumentation system, called ASPIC [Amgoud et al., 2006] and on its extension ASPIC+ [Prakken, 2010, Modgil and Prakken, 2013], which (i) allows the expression of logical arguments as a combination of atoms and rules, (ii) defines attack and defeat relations among arguments based on a logical conflict relation. The main contributions of the work are the following:

1. An instantiation of ASPIC argumentation system $(A S)$ in a DSS dedicated to the selection of packaging solutions well suited for a given food product. 
2. The study of the mutual influences between arguments expressed over several options regarding different concerns. We show the limitation of the regular instantiation of the ASPIC $A S$, and we propose to overcome this limitation with a viewpoint approach in which arguments are gathered according to packaging aspects or concerns. Each viewpoint delivers subsets of non-conflicting arguments supporting or opposing a kind of packaging according to a single topic (shelf life, cost, material type, safety, end of life, etc.).

3. The use of the argumentation results for a multi-criteria flexible querying of the packaging database. The coupling of both components provides a new multi criteria decision making tool dedicated to packaging selection taking into account potentially contradictory stakeholders' preferences.

4. Implementation of the approach as a java GXT/GWT web application accessible on http://pfl.grignon.inra.fr/EcoBioCapProduction/. A demonstration video is also accessible on http://umr-iate.cirad.fr/FichiersComplementaires/DemoRomeHD.mp4.

5. Evaluation of the argumentation tool within the EcoBioCap project with a collaboration of the experts of packaging industry.

In Section 2, we detail the main functionalities of the developed argumentation tool. In Section 3, we introduce the main architecture of the developed 
argumentation system. In Section 4, we recall briefly our approach defining an argumentation theory relying on ASPIC. Then, we explain through a real world example the rationale behind the notion of viewpoints in Section 5 . Section 6 is dedicated to the implementation and evaluation of the approach. Section 7 sums up some related works, and finally, in Section 8 we recall our contributions and introduce some perspectives.

\section{Functional specification of the argumentation} process

We detail hereinafter the main functions of the argumentation system integrated into the EcoBioCap Decision Support System. After discussions and interviews with the project partners, we have identified some requirements summarized in the following functionalities:

- Formalize text arguments: the argumentation system should provide users with a user-friendly interface allowing them to express their arguments as text and then formalizing them as concepts and rules. Here, concepts can be linked to corresponding attributes of the packaging database to permit the exportation of consensual preferences computed by the argumentation system towards the multi-criteria flexible querying of the packaging database. The system should also be equipped with a function of import/export formalized arguments into/from an 
XML format. Thus, one can load already formatted concepts and rules directly in the system.

- Process arguments: the system should automatically compute the logical arguments obtained from the set of concepts and rules. The arguments can be gathered into pros and cons with regard to some packaging alternative characteristics which are discussed by the stakeholders (for example, the end of life characteristics of the packaging: biodegradable, recyclable, etc). Once logical arguments are built, the system should compute all conflicts or attacks among them.

- Compute extensions: an extension is the result of the argumentation process and corresponds to a subset of non-conflicting arguments. The system should implement different kinds of semantics proposed in the literature (admissible, preferred, grounded, stable, etc.). In this way, the user would be able to compute the extensions associated to a particular semantics or to all semantics.

- Enrich the multi criteria flexible querying: based on the obtained extensions, the system should be able to automatically translate the extension into preferred values associated with attributes of the packaging database. These attributes and eventually associated values become predicates (conditions) which can be used later to enrich the multi criteria flexible query which can be processed by the flexible querying system of the DSS. 


\section{Architecture of the argumentation system}

As illustrated in Figure 2, the proposed argumentation system relies on 5 main modules which implement the argumentation work flow, described below.

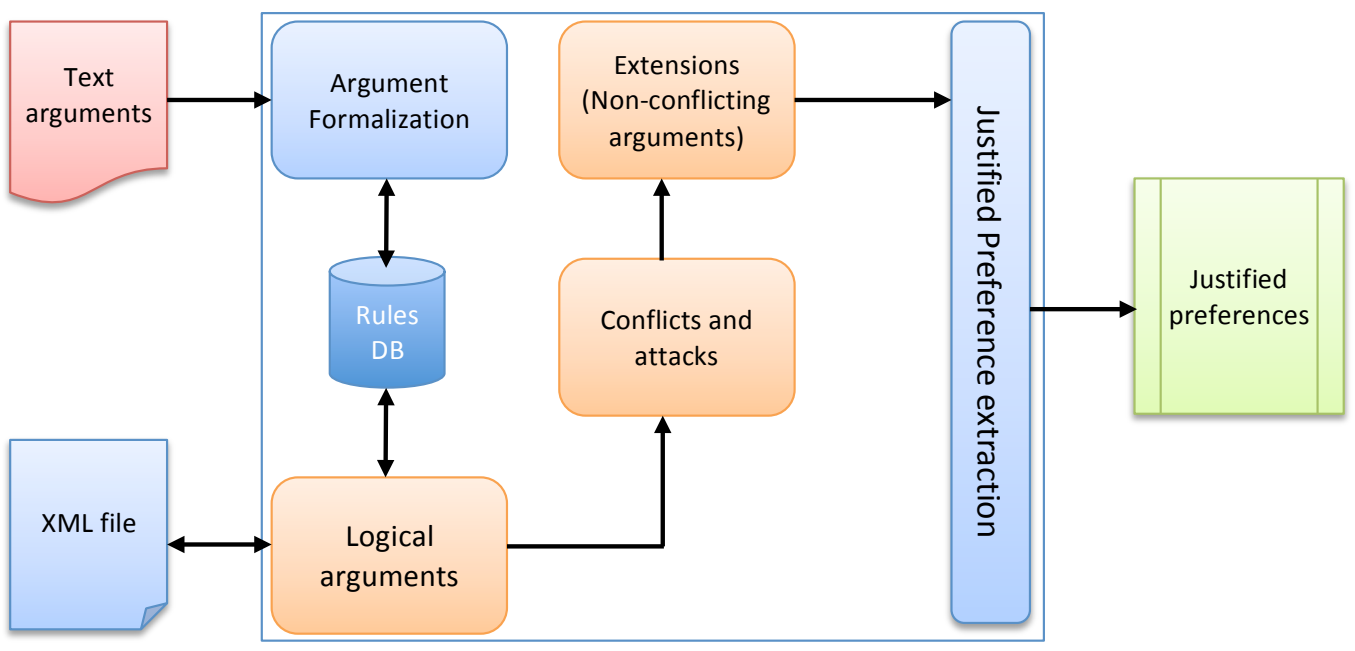

Figure 2: The architecture of the argumentation system.

- Step 1: Argument formalization: this module implements a user-friendly interface for an interactive translation of text arguments into a formal representation made of concepts and rules. A graphical representation of the expressed rules is also built as the users formalize manually their text arguments. The formal representation obtained is finally saved in a database for a persistent storage allowing to reload argumentation projects without rebuilding all the arguments and to reuse also the already formatted rules in other projects. 
- Step 2: Logical arguments building: this module receives as inputs the list of concepts and rules corresponding to text arguments. This list can be the result of the formalization module or given by the user as an XML file. Then, by a derivation process, this module builds all possible arguments according to the process defined in ASPIC $/ \mathrm{ASPIC}+$ logicbased argumentation frameworks [Amgoud et al., 2006, Prakken, 2010] and reused in [Tamani et al., 2013, Tamani et al., 2014]. This module also implements a function to export the argument list into an XML file.

- Step 3: Conflicts and attacks detection: this module relies on the logical arguments built by the previous module. According to the negation operator, it detects all the conflicts among arguments and models them as attacks with respect to the definition of attacks introduced in [Tamani et al., 2013, Tamani et al., 2014]. The output of this module is an argumentation graph made of arguments (nodes) and attacks (edges)

- Step 4: Extensions computation: an extension is a subset of nonconflicting (consistent) arguments which defend themselves from attacking arguments. The computation of extensions is made under one semantics (preferred, stable, grounded, etc.) as defined in [Dung, 1995]. This module allows the computation of one or all semantics considered (preferred, stable, grounded, eager, semi-stable, naive). 
- Step 5: Extraction of the justified preferences: the computation of extensions delivers one or several extensions. In the case of several extensions, the system lets the users select the most suitable extension according to their objectives. If the users cannot reach an agreement over the extensions, the system allows them to add new arguments and re-compute the extensions on the fly. Finally, the selected extension is then used to extract corresponding preferences underlying the contained concepts. These preferences are expressed as a list of couples (attribute, value), where attribute stands for a packaging attribute as defined in the packaging database schema of the flexible querying system part of the DSS, and value is the preferred value expressed for the considered attribute.

In the next section, we introduce the logical language developed for argument formalization.

\section{The argumentation framework}

We recall in this section the Dung abstract framework for argumentation (see subsection 4.1) and we instantiate it with the ASPIC framework (see subsection 4.2). 


\subsection{Dung argumentation principles}

A Dung abstract argumentation framework $(A F)$ [Dung, 1995] is a tuple $(\mathcal{A}, \mathcal{C})$, where $\mathcal{C} \subseteq \mathcal{A} \times \mathcal{A}$ is a binary attack relation on the set of arguments $\mathcal{A}$. For each argument $X \in \mathcal{A}, X$ is acceptable with regard to a set of arguments $S \subseteq \mathcal{A}$ if and only if any argument attacking $X$, is attacked by an argument of $S$. A set of arguments $S \subseteq \mathcal{A}$ is conflict free if and only if $\forall X, Y \in S,(X, Y) \notin \mathcal{C}$. For any conflict free set of arguments $S, S$ is a naive extension [Bondarenko et al., 1997, Coste-Marquis et al., 2005] if and only if it is maximal with respect to $\subseteq, S$ is an admissible extension if and only if $X \in S$ implies $X$ is acceptable with regard to $S . S$ is a complete extension if and only if $S$ is an admissible extension and $X \in S$ whenever $X$ is acceptable with regard to $S ; S$ is a preferred extension if and only if it is a set inclusion maximal complete extension; $S$ is the grounded extension if and only if it is the set inclusion minimal complete extension; $S$ is a stable extension if and only if it is preferred and $\forall Y \notin S, \exists X \in S$ such that $(X, Y) \in \mathcal{C} . \quad S$ is called a semi-stable extension [Baroni et al., 2011, Caminada et al., 2011] if and only if $S$ is a complete extension where $S \cup S^{+}$is maximal, where $S^{+}$is the set of arguments attacked by those of $S . S$ is the eager extension [Baroni et al., 2011] if and only if it is the greatest admissible set that is a subset of each semi-stable extension.

Example 1. In figure 3 below, examples of extensions are presented on different argumentation graphs using Dung's semantics (\{admissible, complete, 


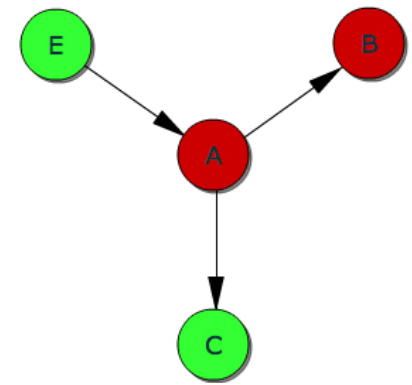

(a) Example of an admissible extension.
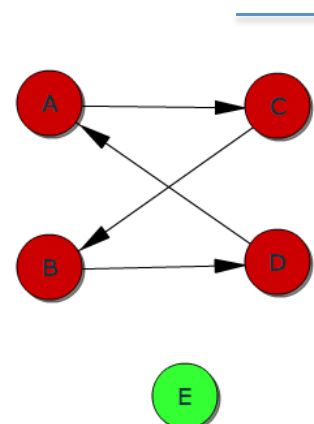

(d) Example of a complete extension. It is also the grounded extension of the argumentation graph.

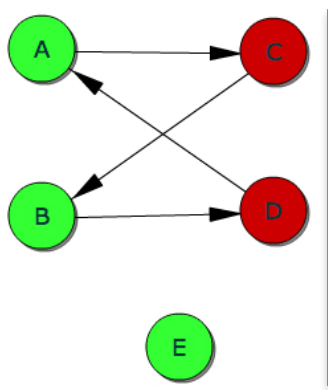

(b)

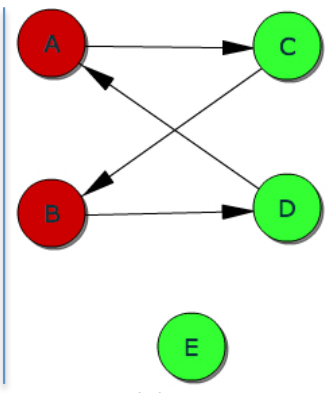

(c)

Examples of preferred and stable extensions.

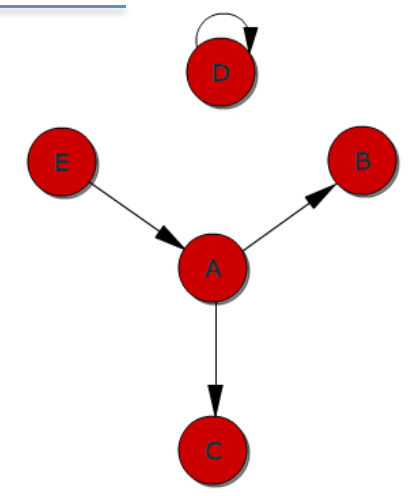

(e) No stable extension.

Figure 3: Examples of extensions under different Dung semantics.

For $T \in\{$ admissible, complete, preferred, grounded, stable, semi-stable, eager, naive \}, $X$ is skeptically (resp. credulously) justified under the $T$ semantics if $X$ belongs to all (resp. at least one) $T$ extension. 
Example 2. In figure 3, sub-graphs $(b)$ and $(c)$ illustrate the two preferred extensions in the argumentation graph. Argument $E$ is skeptically accepted under preferred semantics since it belongs to both preferred extensions, whereas arguments $A, B, C$ and $D$ are credulously accepted under preferred semantics.

We notice that some semantics can return empty or even no extensions. This situation occurs particularly when a user expresses at least one selfdefeated argument, which is not attacked by any other argument, but attacks all the others. This kind of arguments are called contaminating arguments [Wu, 2012]. The current version of our system detects the rules leading to such arguments and discards them before performing the process of extension computations. The user is warned and the list of discarded rules is displayed.

\subsection{ASPIC argumentation system}

In this paper we consider a subset of ASPIC $+[$ Prakken, 2010] argumentation system, which is compatible with the ones presented in [Amgoud et al., 2006]. An $\mathrm{ASPIC}+$ argumentation system is denoted $A S=(\mathcal{L}, c f, \mathcal{R}, \geq)$, where:

- $\mathcal{L}$ is the logical language of the system.

- $c f$ is a contrariness function which associates to each formula $f$ of $\mathcal{L}$ a set of its incompatible formulas (in $2^{\mathcal{L}}$ ): in our case, $c f$ corresponds to classical negation $\neg$.

- $\mathcal{R}=\mathcal{R}_{s} \cup \mathcal{R}_{d}$ is the set of strict $\left(\mathcal{R}_{s}\right)$ and defeasible $\left(\mathcal{R}_{d}\right)$ inference 
rules where $\mathcal{R}_{s} \cap \mathcal{R}_{d}=\emptyset$. As stated in [Modgil and Prakken, 2013], ASPIC+'s inference rules can be used to encode domain-specific information but they could also express general laws of reasoning. In this paper we use these rules to encode packaging domain-specific information. Thus, a strict rule, denoted by $\rightarrow$, expresses a natural implication in the domain, as "GlutenPackaging is a Packaging", and a defeasible rule, denoted by $\Rightarrow$, expresses an implication which is not always true, as "GlutenPackaging can be a suited Packaging". For each strict rule $a \rightarrow b$, we add in $\mathcal{R}_{s}$ the rule $\neg b \rightarrow \neg a$ to ensure the completeness and the consistency of reasoning (see [Caminada and Amgoud, 2007] for further details),

- $\geq$ is a preference ordering over defeasible rules, not used in our framework.

A knowledge base in an $A S=(\mathcal{L}, c f, \mathcal{R}, \geq)$ is $\mathcal{K} \subseteq \mathcal{L}$, which contains the concepts defined in the domain and the alternative choices under discussion.

Argument structure. An ASPIC argument $A$ can be of the following forms:

1. $c$ with $c \in \mathcal{K}$, such that $\operatorname{Prem}(A)=\{c\}, \operatorname{Sub}(A)=\{A\}$ and $\operatorname{Conc}(A)=$ $c$, with Prem returns premises of $A, S u b$ returns its sub-arguments and Conc returns its conclusion,

2. $A_{1}, \ldots, A_{m} \Rightarrow c\left(\right.$ resp. $\left.A_{1}, \ldots, A_{m} \rightarrow c\right)$, such that there exists a strict 
(resp. defeasible) rule in $\mathcal{R}_{s}$ (resp. $\mathcal{R}_{d}$ ) of the form $\operatorname{Conc}\left(A_{1}\right), \ldots, \operatorname{Conc}\left(A_{m}\right) \Rightarrow c\left(\right.$ resp. $\left.\operatorname{Conc}\left(A_{1}\right), \ldots, \operatorname{Conc}\left(A_{m}\right) \rightarrow c\right)$, with $\operatorname{Prem}(A)=\operatorname{Prem}\left(A_{1}\right) \cup \ldots \cup \operatorname{Prem}\left(A_{m}\right), \operatorname{Conc}(A)=c, \operatorname{Sub}(A)=$ $\operatorname{Sub}\left(A_{1}\right) \cup \ldots \cup \operatorname{Sub}\left(A_{m}\right) \cup\{A\}$.

Form 1 associates one argument with each alternative choice defined in the argumentation system $A S$. Based on arguments generated by Form 1, Form 2 permits to create new arguments by applying a derivation process over the set of strict $\left(\mathcal{R}_{s}\right)$ and defeasible $\left(\mathcal{R}_{d}\right)$ rules defined in $A S$. A step in the derivation process considered in this case means that, if a set of final conclusions of a given set if arguments matches the antecedents of a rule then the arguments can be combined by applying the rule, thus creating a new argument. Each step in this derivation process forms an argument. We make the assumption that the set of arguments constructed from the argumentation system is finite. An argument is said strict if and only if it does not involve any defeasible rules. Otherwise, it is called defeasible.

The set of strict rules $\mathcal{R}_{s}$ is consistent if and only if it is impossible to construct in the argumentation system two strict arguments having conflicting conclusions ( $\nexists A, B$ such that $A, B$ are strict arguments and $\operatorname{Conc}(A)=$ $\neg \operatorname{Conc}(B))$.

Notation. To improve the readability, by abuse of notation, we associate to each argument a label made of a capital letter followed by a subscript number. The labels are then used in an argument to refer to its sub-arguments. In 
this notation, a label followed by colon is not a part of the argument.

Let $A S$ be an ASPIC argumentation system defining the strict rule $a, b \rightarrow c$ and the alternative choices $a, b$. The knowledge base is $\mathcal{K}=\{a, b, c\}$. The set of strict rules (closed under transposition) is $\mathcal{R}_{s}=\{a, b \rightarrow c ; \neg c, b \rightarrow$ $\neg a ; a, \neg c \rightarrow \neg b\}$. The following arguments can be built:

- $A_{1}: a$

- $A_{2}: b$

- $A_{3}: A_{1}, A_{2} \rightarrow c$.

$A_{3}$ means that $\operatorname{Conc}\left(A_{1}\right)$ and $\operatorname{Conc}\left(A_{2}\right)$ are the hypothesis that lead to the claim $c$, by applying the rule $a, b \rightarrow c$.

Example 3. We consider the following textual arguments expressed about biodegradability of packaging materials.

- Life Cycle Analysis (LCA) results are not in favor of biodegradable materials, regarding their high environmental impact during the production process.

- Consumers are in favor of biodegradable materials since they could help to protect the environment.

We model these arguments by using the proposed logical language as follows: 
- $B P$ is a concept referring to biodegradable packaging materials.

- PEV, HIP are concepts referring to packagings which respectively protect the environment and have a high environmental impact (according to LCA).

- $A C C, R E J$ are concepts referring to the global decisions (accepted, rejected) about the packaging to choose according to the aspect considered (in this example, the biodegradability of the material). Intuitively, $A C C=\neg R E J$ and $R E J=\neg A C C$. We can syntactically replace $R E J$ with $\neg A C C$.

The set of rules $\mathcal{R}=\mathcal{R}_{s} \cup \mathcal{R}_{d}$ is:

- $\mathcal{R}_{s}=\{B P \rightarrow H I P, \neg H I P \rightarrow \neg B P, H I P \rightarrow \neg A C C, A C C \rightarrow \neg H I P\}$

- $\mathcal{R}_{d}=\{B P \Rightarrow P E V, P E V \Rightarrow A C C\}$

Please notice that strict rules are used to model reliable knowledge based on measured parameters by using well-defined and stated procedures, or expressed with linguistic terms such as "must", "shall", "mandatory", "important", etc. On the other hand, defeasible rules model knowledge based on empirical observations or expressed with linguistic terms such as "may", "could", "optional", etc. Here, the rules involve HIP are considered as strict and those involving $P E V$ are defeasible.

The following structured arguments can be built on the knowledge base $\mathcal{K}=\mathcal{K}_{p}=\{B P\}$ 
357
- $A_{0}: B P$

- $A_{1}: A_{0} \rightarrow H I P$

- $A_{2}: A_{1} \rightarrow \neg A C C$

- $B_{1}: A_{0} \Rightarrow P E V$

- $B_{2}: B_{1} \Rightarrow A C C$

- $B_{3}: B_{2} \rightarrow \neg H I P$

- $B_{4}: B_{3} \rightarrow \neg B P$

ASPIC/ASPIC + attack and defeat relations. We only consider in this work the rebutting attack as defined in [Modgil and Prakken, 2013]:

Argument $A$ rebuts argument $B$ on $B^{\prime}$ if and only if $\operatorname{Conc}(A) \in c f(\varphi)$ (where $\varphi$ is an atom in the language) for some $B^{\prime} \in S u b(B)$ of the form $B_{1}^{\prime}, \ldots, B_{m}^{\prime} \Rightarrow \varphi$.

Finally, $A$ defeat $B$ if $A$ rebuts $B$.

Example 4. Let us consider the arguments built in Example 3. Argument $A_{2}$ rebuts argument $B_{2}$ since $\operatorname{Conc}\left(B_{2}\right)=A C C$ and $\operatorname{Conc}\left(A_{2}\right)=\neg A C C$ and $B_{2}: B_{1} \Rightarrow A C C$, which means that $A C C$ stems from a defeasible rule, therefore it is less strong than $A_{2}$ and $B_{2}$ cannot attack $A_{2}$. Then, $A_{2}$ defeats $B_{2}$. 
Extension output. The output of an extension $\mathcal{E}$ is defined as the union of the conclusion of its arguments: $\operatorname{Output}(\mathcal{E})=\operatorname{Concs}(\mathcal{E})=\{\operatorname{Conc}(A), A \in$ $\mathcal{E}$ \}, where $\operatorname{Conc}(A)$ is the conclusion of argument $A$.

Example 5. Let us consider again the arguments built in Example 3. Only one preferred extension $\mathcal{E}_{1}=\left\{A_{0}, A_{1}, A_{2}, B_{1}\right\}$ can be computed over this set of arguments. The output of $\mathcal{E}_{1}$ is $\operatorname{Output}\left(\mathcal{E}_{1}\right)=\operatorname{Concs}\left(\mathcal{E}_{1}\right)=$ $\{B P, H I P, P E V, \neg A C C\}$.

It is worth noticing that as we obtain only one extension then all its arguments are both skeptically and credulously accepted in the argumentation system, under the preferred semantics.

In the following, we detail how this argumentation system has been instantiated with the EcoBioCap project knowledge.

\section{ASPIC instantiation for packaging selection application}

In this section we introduce the instantiation of our logical representation of text arguments within ASPIC AS. We describe in Subsection 5.1 how textual arguments are modeled as options and rules, which are used after that to instantiate ASPIC $A S$ for argument derivation, conflict detection, extension computation and predicate extraction. We show in Subsection 5.2 the drawback of a direct instantiation of the ASPIC argumentation system in 
our application context and we introduce our solution based on viewpoints.

\subsection{Logical modeling of text arguments in ASPIC $A S$}

As described in Section 3, we aim at developing an argument-based application for packaging selection in order to be able:

- to model logically the stakeholders' arguments in order to extract the underlying knowledge that could enrich the querying process,

- to compute the extensions (the subsets of consistent arguments that defend themselves against attacks),

- to extract from the chosen extension the predicates to use in the querying process, called justified preferences.

The first requirement can be achieved by defining two levels of modeling: syntactical level and logical level. At the syntactical level, we identify in each argument the concepts involved, their corresponding attributes in the database and optionally the values associated with attributes. A concept is seen as a subclass of packaging. The concepts syntactically correspond to the atoms of the propositional language used to instantiate the argumentation framework. At the logical level, we distinguish for each argument the body (or the premises) and the head (or the conclusion) of the underlying rules and we specify if the extracted rule is either strict or defeasible. The body and the head of a rule correspond to concepts defined at the syntactical level. 
Example 6. Let us consider the following argument:

"Life Cycle Analysis (LCA) results are not in favor of biodegradable materials, regarding their high environmental impact during the production process, expressed by the carbon footprint $\geq 5 \mathrm{~kg}$ eq. $\mathrm{CO}_{2}{ }^{\prime \prime}$.

At the syntactical level, we define the following concepts:

- BiodegradablePackaging: it corresponds to the biodegradable packaging; it is related to the attribute Biodegradability which is already defined in the database schema and to the value TrueBiodegradablePackaging also defines one of the possible choices of packaging, which are discussed in the argumentation system.

- HighEnvImpactPackaging: it corresponds to packaging having a bad carbon footprint value. This concept is related to the attribute CarbonFootPrint and the value $\geq 5 \mathrm{~kg}$ eq. $\mathrm{CO}_{2}$. In the case that the attribute is not defined in the database schema; the application allows, however, the user to add the required information to define it (value type, measure unit, minimal value, etc.), and to suggest it as a possible extension of the database schema.

At the logical level, the argument is translated into the following rules:

- BiodegradablePackaging $\rightarrow$ HighEnvImpactPackaging

- HighEnvImpactPackaging $\Rightarrow$ NotAccepted

These rules express the fact that each biodegradable packaging is a packaging having a high environmental impact (considered here as strict for the 
sake of demonstration), and such packaging are not accepted or rejected (represented as a defeasible rule as a decision is generally defeasible). The user specifies both rules at once using the same user interface, and indicates also for each rule if it is strict or defeasible. The application automatically adds the transposed rule in the case of strict rules.

The rules and the options (seen as premises), in addition to the decision atoms Accepted and Not Accepted, are used to instantiate the ASPIC $A S$. Once ASPIC $A S$ is instantiated, the system derives the arguments (as illustrated in Example 3), detects the conflicts amongst them (as in Example 4), computes the extensions (like in Example 5), and finally extracts the predicates to send to the querying process. As illustrated in Example 5, the argumentation system recommends the rejection of the biodegradable packaging. This recommendation is translated into the predicate Biodegradable $=$ False, which can be expressed in a SQL query. This query is afterwards addressed to the database containing the packaging materials in order to retrieve the packaging which are not biodegradable.

In the next subsection, we show the limitation of a direct instantiation of the ASPIC $A S$ based on our logical approach for argument modeling, and we introduce a solution relying on viewpoints.

\subsection{Viewpoint-based ASPIC $A S$ for packaging selection}

When stakeholders are engaged in an argumentation process, they express their arguments for or against the acceptance of some kinds of packagings 
477

according to some characteristics, corresponding to their concerns and objectives. Let us consider the following text arguments expressed by the stakeholders obtained by interviews and surveys.

1. Packaging materials with low environmental impact are preferred, low environmental impact corresponds to carbon footprint of value $[0,10]$ kg $\mathrm{CO}_{2}$,

2. Waste management authority aims at collecting at least $75 \%$ of recyclable packaging,

3. Consumers are unwilling to sort packaging cause of its extra tax,

4. Life Cycle Analysis (LCA) results are not in favor of biodegradable and compostable materials,

5. Consumers are in favor of biodegradable material because they help to protect the environment,

6. Biodegradable materials could encourage people to throw their packaging in nature, causing visual pollution,

7. Micro-perforated packaging can increase the shelf life by about 20 days,

8. Multilayered byproduct made packagings allow a good permeance,

9. Multilayered byproduct made packagings are generally expensive to produce, 
10. Mono-layered byproduct made packagings are easier to produce,

11. Consumers do not want to pay an extra cost greater than $5 \%$ for a product packed with biodegradable or compostable packaging,

12. According to the waste management agency, recycling can create new job opportunities.

Here, we distinguish several packaging options: Biodegradable, Recyclable, Compostable, Micro-Perforated, Multilayered, Mono-layered packagings.

Let us consider all the above mentioned arguments to instantiate an AS$\mathrm{PIC} / \mathrm{ASPIC}+$ argumentation system. In this case, the argumentation system returns extensions (in any Dung semantics) which are not enough informative to make a decision, as shown by the following instantiation limited to arguments 5 and 9 (but without loss of generality):

Example 7. Arguments 5 and 9 are defeasible and involve two different options: Biodegradable (denoted by Bio) and Multi-layered (denoted by Mul) materials. A classical ASPIC argumentation system derives from these text arguments the following 6 logical arguments:
- $A_{0}: B i o$
- $A_{1}: A_{0} \Rightarrow$ ProtectEnvironment
- $A_{2}: A_{1} \Rightarrow$ Accepted
- $B_{0}: M u l$ 
- $B_{1}: B_{0} \Rightarrow$ Expensive

- $B_{2}: B_{1} \Rightarrow$ Not Accepted

Argument $A_{2}$ attacks Argument $B_{2}$ and vice-versa and we get 2 preferred extensions:

- $\mathcal{E}_{1}=\left\{A_{0}, A_{1}, A_{2}, B_{0}, B_{1}\right\}$

- $\mathcal{E}_{2}=\left\{A_{0}, A_{1}, B_{0}, B_{1}, B_{2}\right\}$

The output of each extension ${ }^{1}$ are as follows:

- $\operatorname{Concs}\left(\mathcal{E}_{1}\right)=\{$ Bio, ProtectEnvironment, Mul, Expensive, Accepted $\}$

- $\operatorname{Concs}\left(\mathcal{E}_{2}\right)=\{$ Bio, ProtectEnvironment, Mul, Expensive, Not Accepted $\}$

We notice that the conclusions of $\mathcal{E}_{1}$ ad $\mathcal{E}_{2}$ are identical, expect for the decision (Accepted, Not Accepted). Therefore, they cannot be used for decision support because their conclusions say that we accept and we reject both options $M u l$ and Bio for the same reasons.

To alleviate this situation, we suggest to separate the options according to the topic or the concern considered. Each topic is called viewpoint, which gathers arguments involving some options or alternatives and dealing with the same subject. Hence, we can handle arguments for both acceptance and rejection of packaging but considered only from one packaging aspect. In this

\footnotetext{
${ }^{1}$ We recall that the output of an extension is the set of its argument conclusion.
} 
way, decisions reached in each viewpoint are based on one packaging aspect debated by stakeholders' arguments.

A viewpoint helps the users to express their arguments by connecting an option with the reason behind its acceptance or rejection. The resulted extensions in a viewpoint not only provide accepted (resp. rejected) options but provide some information explaining why they are accepted (resp. rejected) as well. A viewpoint facilitates the analysis of the output of the argumentation framework for decision making, since we get one extension which contains the accepted options and all the reasons leading to their acceptance, and a second extension which contains the rejected options and all the reasons leading to their rejection.

Each viewpoint instantiates our logical approach for argument modeling. Decisions can then be made relying on the computed extensions corresponding to the consensual solutions from a single packaging attribute. We then obtain several attributes with their related values, which are finally used to enrich the querying process for packaging selection, handled by the multicriteria flexible querying system.

It is worth noticing that this approach is a simplification of a theoretical viewpoint model introduced in [Tamani et al., 2013].

Example 8 (Cont. Example 7). In the above example, the first argument deals with the end of life characteristics of the material to use, and the second argument deals with the design of the packaging. Thus, we can 
consider two viewpoints: End of life and Design. Each viewpoint instantiates an ASPIC argumentation system. We here obtain one preferred extension per viewpoint:

- $\mathcal{E}_{\text {End_of_life }}=\left\{A_{0}, A_{1}, A_{2}\right\}$ from which we extract the predicate

"Biodegradability = True",

- $\mathcal{E}_{\text {Design }}=\left\{B_{0}, B_{1}, B_{2}\right\}$ from which we extract the predicate

"Multilayered = False".

Both predicates are finally available for the querying process to retrieve from the database the packaging material satisfying them. The user can select both predicates since they are not contradictory or just one of them, which is considered as the most important predicate according to his/her needs. It amounts to decide which of the viewpoints is the most important for his/her query.

The above twelve arguments can be split into the following viewpoints:

- end of life: in this viewpoint, stakeholders (waste management authority, users, researchers) argue between biodegradability, compostability and recyclability of the packaging. It contains arguments 1 to 6,11 and 12 ,

- design for a better shelf life: this viewpoint contains arguments 7 to 10, the choice is between mono-layered, multilayered and micro-perforated packagings. 
It is worth noticing that there is not a crisp boundary between viewpoints and it is possible to have arguments expressed on more than one aspect of packaging. For instance, arguments 11 and 12 could be gathered into a new viewpoint about the economic concerns. For the sake of flexibility, the current version of the system does not impose any restriction on the process of affectation of the arguments to the viewpoints. In addition, it allows users to duplicate such arguments in more than one viewpoint to see their effects on different aspects of packaging.

The benefits of viewpoints are the following:

- Helping the stakeholders to express their argument by considering one topic at a time, and to analyse the results delivered from the argumentation framework.

- Associating subsets of arguments to attributes defined in the database schema. It facilitates the querying process, which retrieves the list of packaging materials.

- Reducing the mutual influence between arguments expressed about different issues.

- Possible reduction of the CPU-time for extension computation, since the number of arguments and attacks to consider is less than all the arguments to handle in the argumentation framework. It has been proven in [Vreeswijk, 2006] that the extension computation is expo- 
nential in time. The higher the number of conflicts among arguments in the system is, the higher the response time for extensions will be.

The drawback of viewpoints lies in the fact that it is possible in some case that a single option is accepted in one viewpoint and rejected in another one, since the argumentation system does not forbid the use of a single option in more than one viewpoint. For instance, biodegradable packaging is acceptable from the environment (end of life) viewpoint but not accepted from the economic viewpoint. The system is designed to be flexible enough to give the experts the ability to decide which extensions to consider and which ones to discard. In this case, as said above, it is up to the user to decide which viewpoint is the most important for the querying process.

In the next section we describe the functionalities implemented of the argumentation system through several screenshots showing the process of instantiation of the argumentation system on the end of life viewpoint as well as the results delivered.

\section{Implementation and evaluation of the argu- mentation approach}

We detail in Subsection 6.1 the implementation of the approach as a webbased application. Then, we evaluate in Subsection 6.2 the argumentation tool for packaging selection according to the end of life viewpoint with experts 
from four european countries (France, Hungary, Italy and Sweden), involved in the EcoBioCap project.

\subsection{Implementation of the argumentation tool}

The implementation of the approach was done in the context of the EcoBioCap DSS. A java GXT/GWT web interface was developed and an open version is accessible on http://pfl.grignon.inra.fr/EcoBioCapProduction/. A short demonstration video is available for download ${ }^{2}$. Hereinafter, some user interfaces are displayed showing the obtained result in the case of the viewpoint "end of life".

The main interface of the system is illustrated in Figure 4. It is divided into 5 zones. Zone 1 corresponds to the task bar implementing general functions applied on projects (create, load, close, refresh, export, etc.). Zone 2 lists the text arguments by stakeholders. Zone 3 displays the extracted concepts and rules from the text arguments, they are also listed by stakeholders. Zone 4 displays the graphical representation of the formalized concepts and arguments. Zone 5 is a notification area displaying the computed conflicts and extensions.

\footnotetext{
${ }^{2}$ http://umr-iate.cirad.fr/FichiersComplementaires/DemoRomeHD.mp4
} 


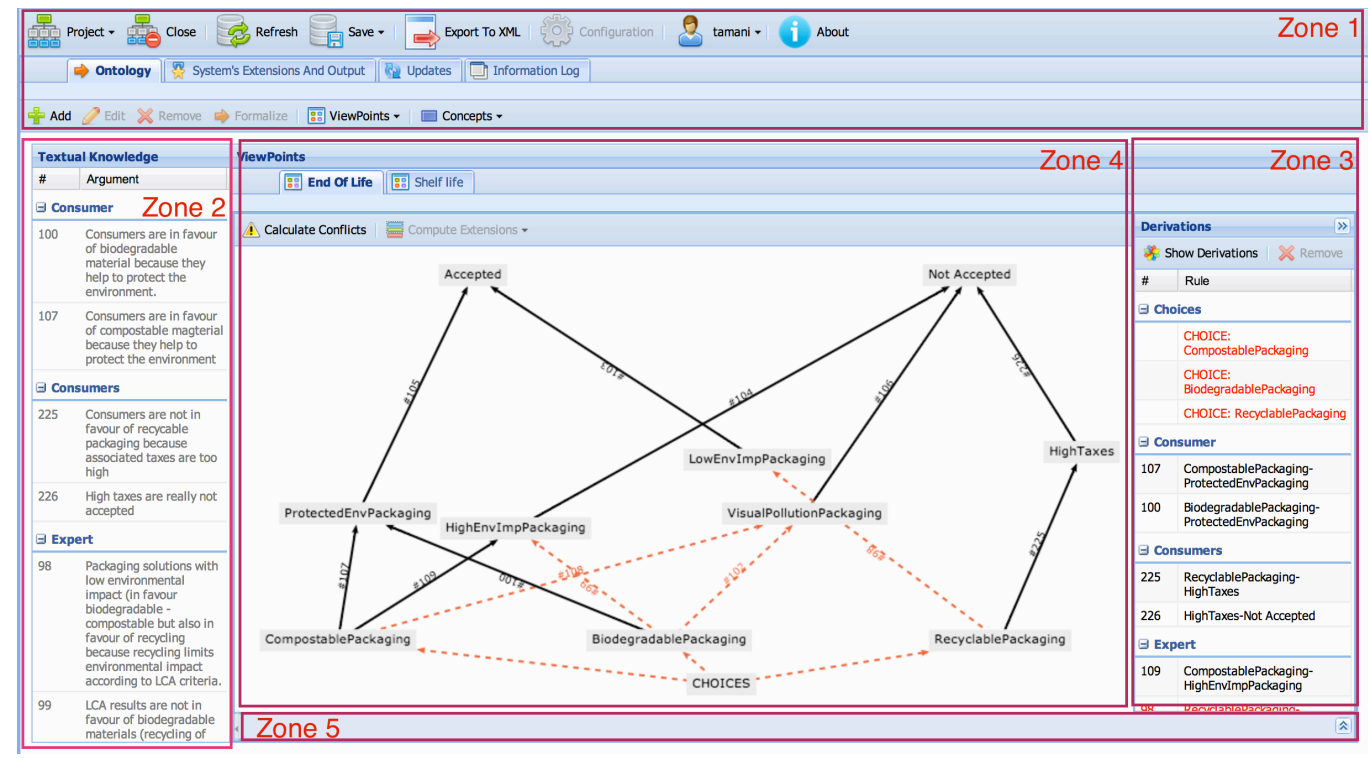

Figure 4: The main interface of the argumentation system.

After logging in, the user can create a new project, load an existing one or import a new project from an XML file. Then, stakeholder arguments can be entered as (i) an XML file, by using the import from XML function, or (ii) text arguments to formalize them as concepts and rules by using a dedicated user interface (Figures 5, 6, 7 and 8) guiding and helping the user during all the process of formalization. A new concept has a name and a short code, it can be defined as either a choice or not and can be related to a packaging attribute (as in Figure 5, BiodegradablePackaging corresponds to packagings having the attribute Biodegradability equals True in the packaging database), not related to any information in the database (as in Figure 6 for the concept HighTaxes), or can suggest a new attribute to 
enrich the packaging description in the database (as in Figure 7, the concept HighEnvPackaging suggests the new attribute CarbonFootPrint, with the measure unit of $\mathrm{KgCO}_{2}$ eq. to describe the packaging).

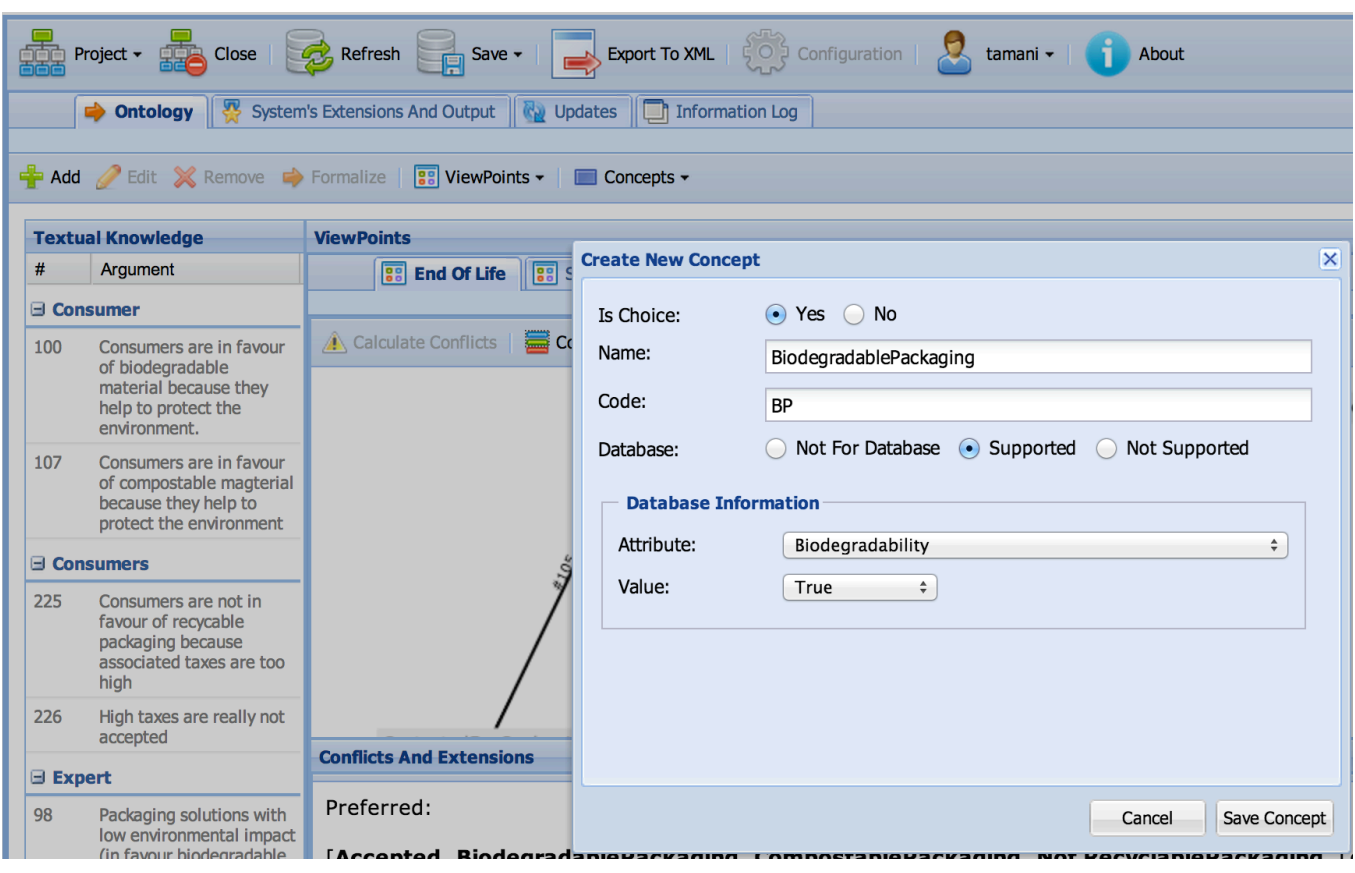

Figure 5: Adding a concept based on a defined attribute in the packaging database. 


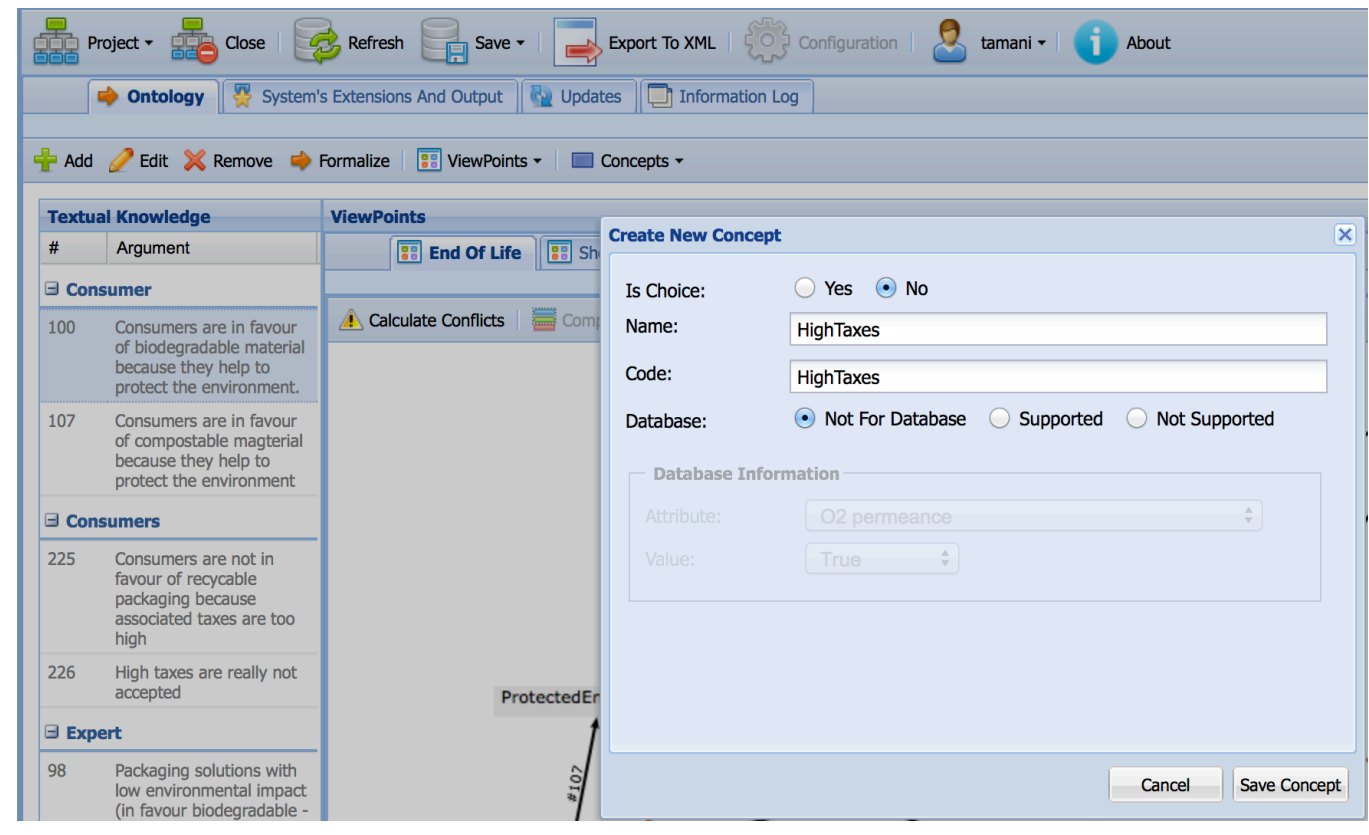

Figure 6: Adding a concept which is not related to the database. 


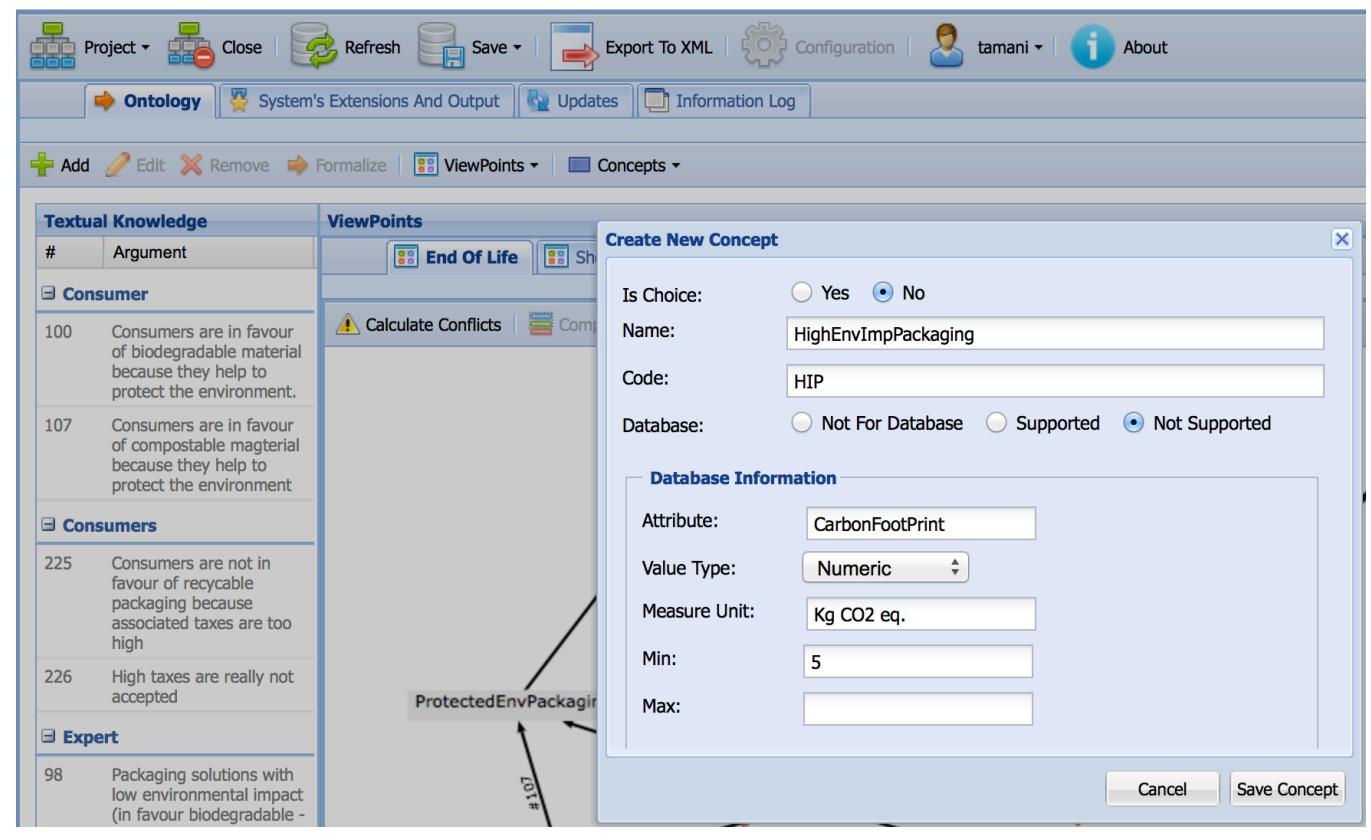

Figure 7: Adding a concept not supported yet in the packaging database but suggested for addition. 


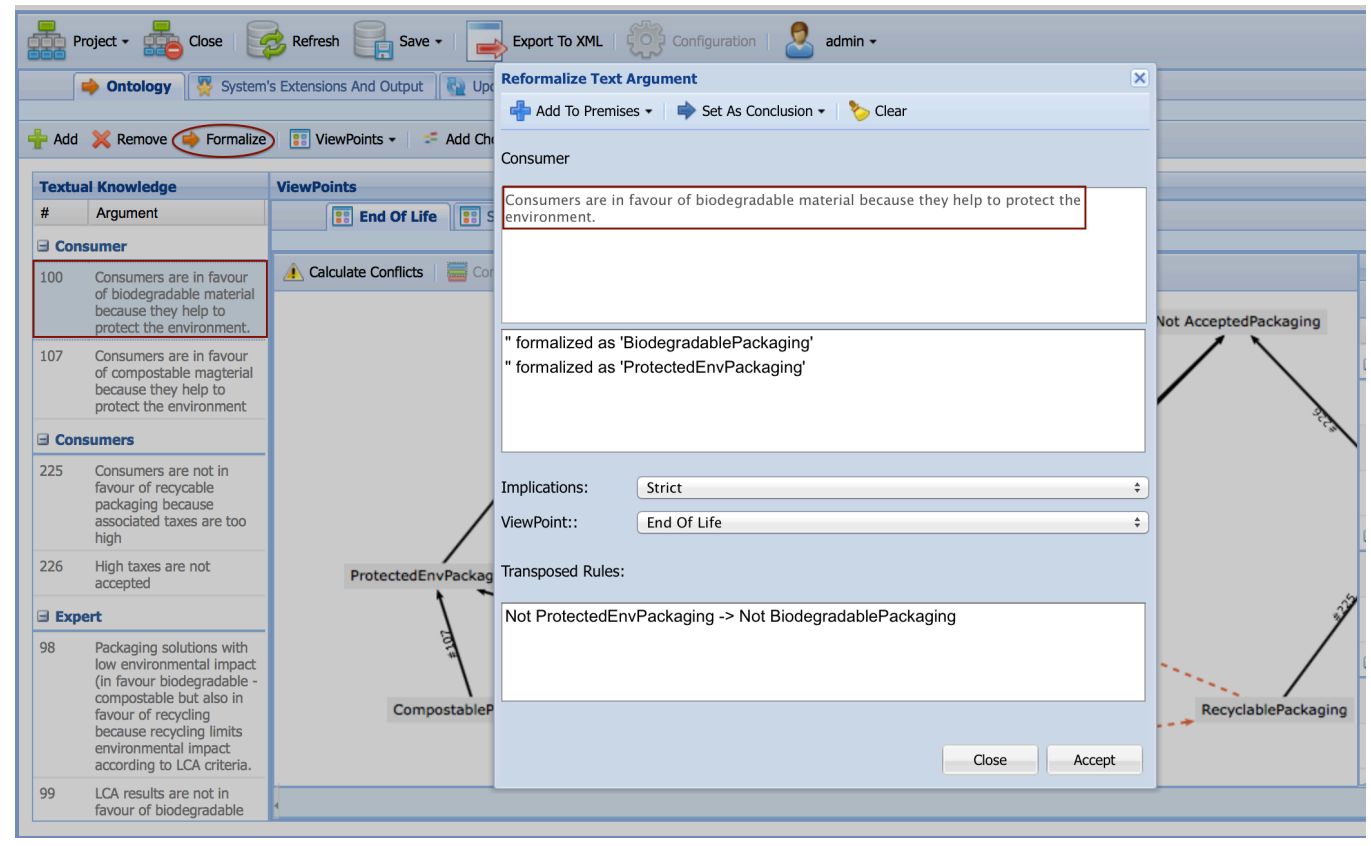

Figure 8: Formalizing a text argument as concepts and rules.

Figure 8 shows the formalizing interface in which a user can select the already created concepts as premise or conclusion to form the rule underlying the text argument. The rule is then connected to a decision (Accepted, Not Accepted). The rule and its decision can be specified either as a strict or as a defeasible rule.

Figure 9 illustrates the obtained rules in the case of the viewpoint end of life in which stakeholders argued about biodegradability, recyclability and compostability. 


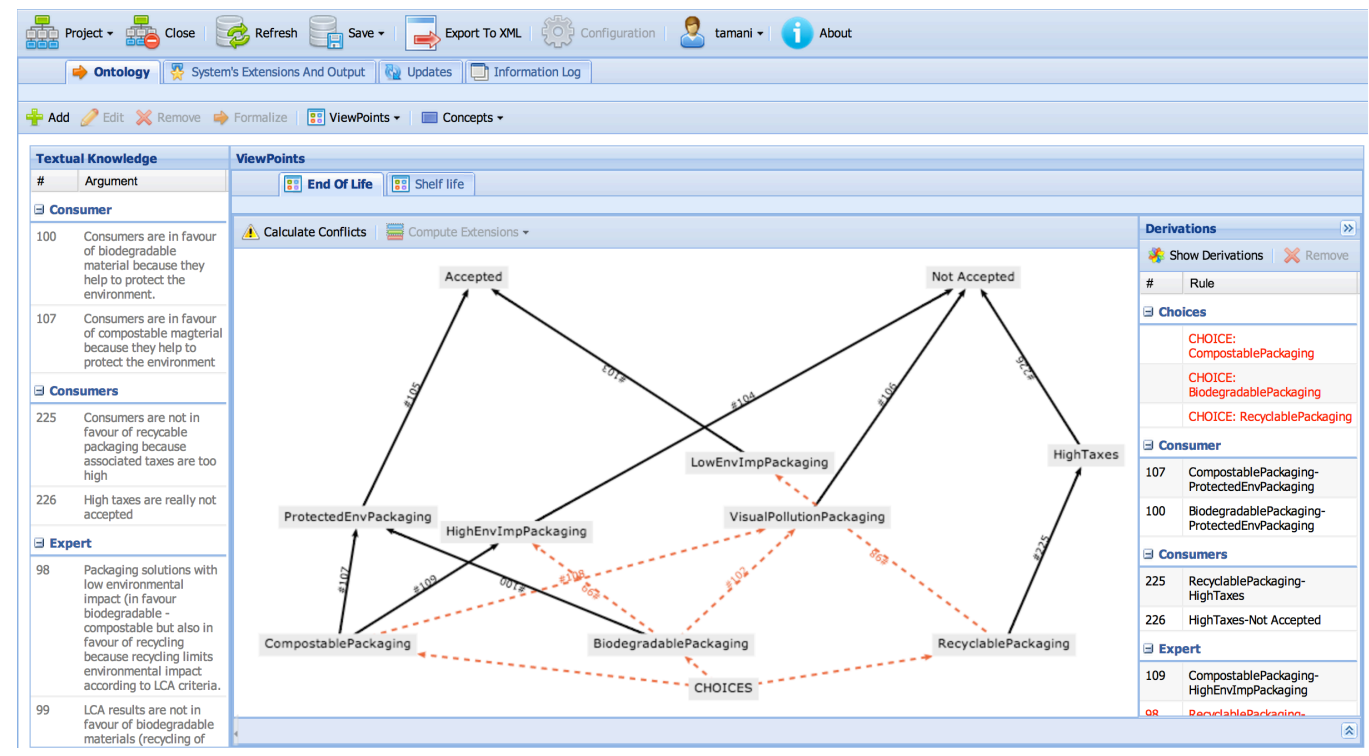

Figure 9: Example of the rules built upon the viewpoint end of life.

639 The system generates arguments and computes conflicts and attacks as 640 shown in Figure 10. For the arguments of end of life viewpoint, the system 641 detected 409 conflicts. 


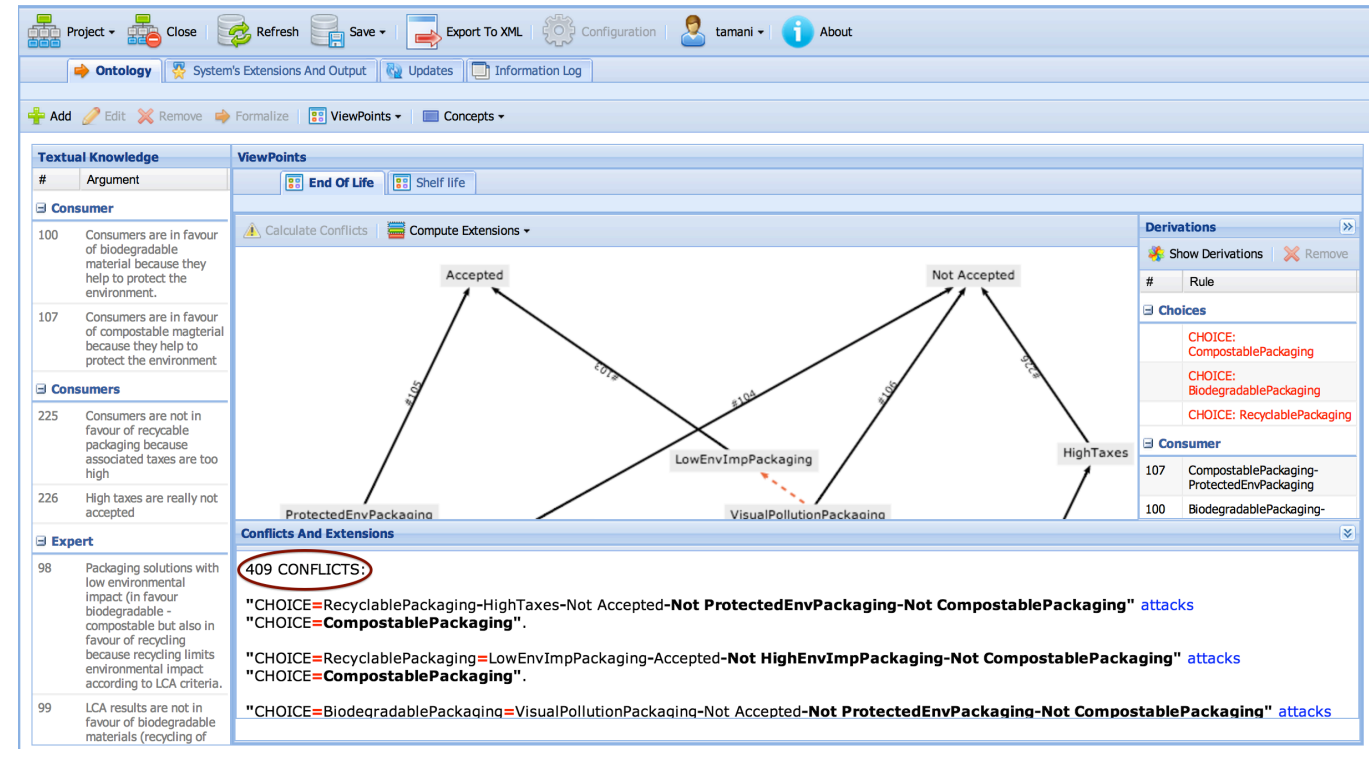

Figure 10: Conflicts computed in the viewpoint end of life.

The extensions under different semantics (stable, preferred, admissible, grounded, naive) are after that computed and their contents are displayed to the user in Figure 11, by using the Java DungAF $\mathrm{API}^{3}$. For the sake of simplicity, we made the design choice to display only the conclusions of the arguments belonging to an extension. To highlight the recommendations in each extension, the concepts playing the role of the choices and decision variables (Accepted and Not Accepted) are displayed in bold font.

It is worth noticing that all the extensions recommending the rejection (Not Accepted) are displayed in a positive way by negating all concepts contained (NOT "Not $C$ " becomes " $C$ " and NOT " $C$ " becomes "Not $C$ " with $C$ is either a concept or a decision). The reason for this translation is to address

\footnotetext{
${ }^{3}$ https://github.com/jtdevereux/javaDungAF
} 


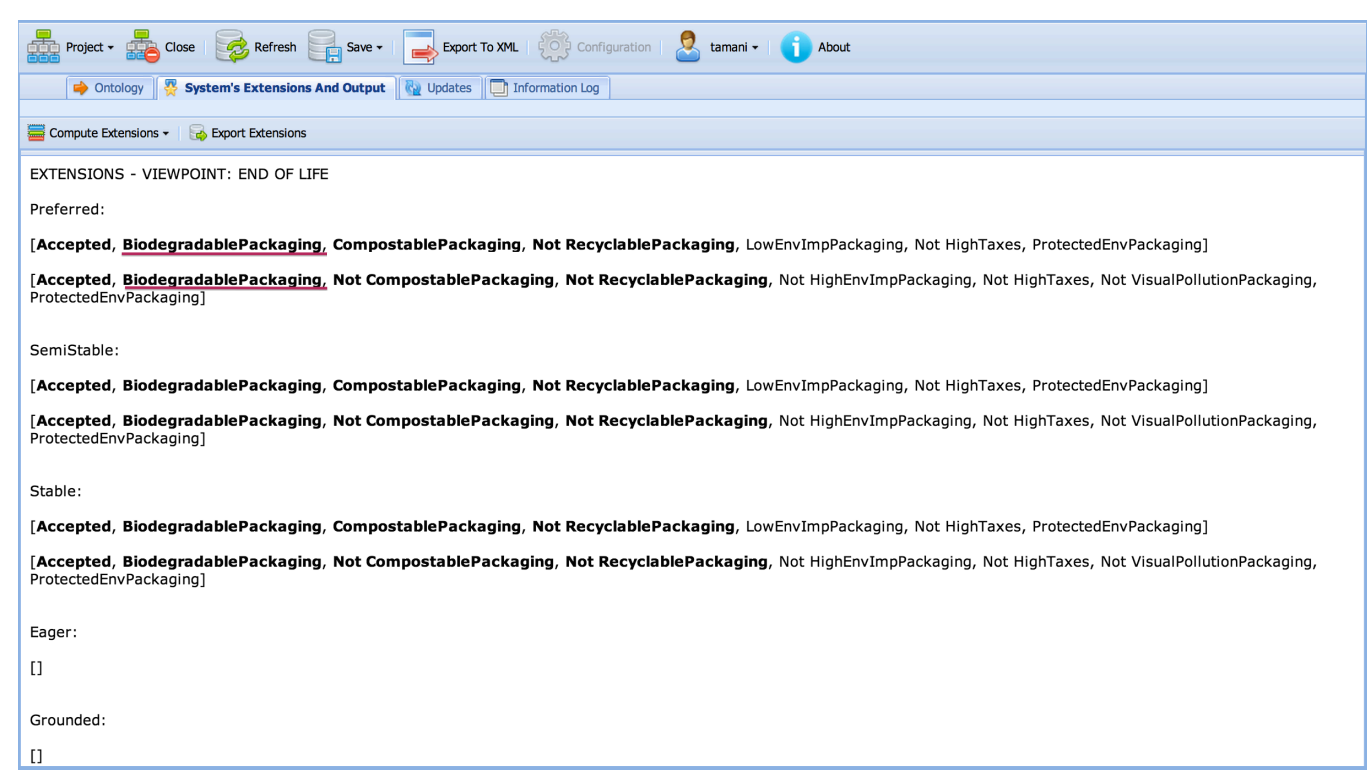

Figure 11: Delivered extensions in the end of life viewpoint.

one of the expert feedbacks obtained during an early test of the user interface. In fact, the experts considered that it is not intuitive to choose an extension recommending a rejection (which contains the decision Not Accepted).

In Figure 11, the system concludes skeptically that biodegradable packagings are the most justified ones under the preferred semantics (the concept underlined in red).

In addition to its ability to aggregate non-structured knowledge expressed as text arguments, the argumentation process also provides the user with some justifications supporting the recommended result. For example, we notice in Figure 11 that biodegradable packagings are accepted because they help protecting the environment (ProtectEnvPackaging), as they have a low 
environmental impact and do not imply any additional taxes (Not HighTaxes) to be paid by the society (industries, population, etc.).

Furthermore, the proposed approach is also dynamic in the sense that if an expert does not agree with the argumentation results, he/she can add on the fly additional arguments to express his/her disagreement. Then, the application detects the conflicts generated by the added arguments and recompute the extensions accordingly.

The extensions obtained are stored as a list of attribute $=$ value (Figure 12) to be used in the flexible querying system in addition to some other parameters useful for the querying process (value 1 and value 2 corresponding to the values $\min$ and $\max$ in Figure 7 , their respective data type: columns Type, the attribute is either negated or not: the column Negated, and finally the attribute is either defined in the database schema or not: the column Supported in DB).

In the context of end of life viewpoint, the condition Biodegradable $=$ True is sent to the querying process to be used as a justified preference for packaging material selection. 


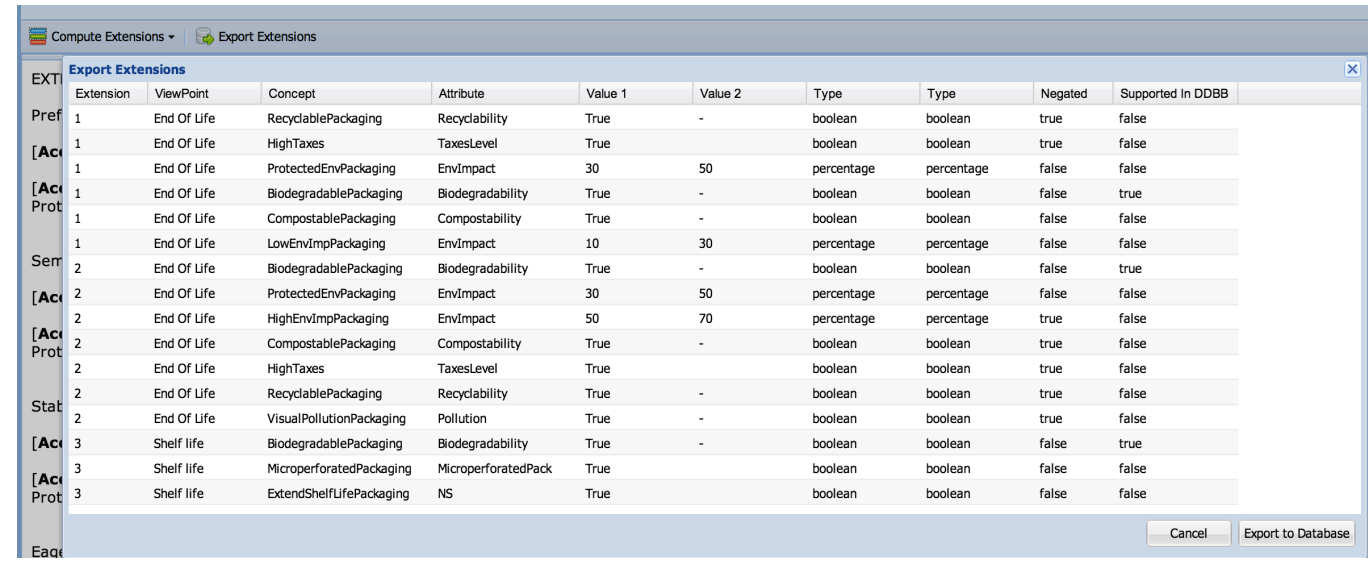

Figure 12: Exporting the extensions composed of concepts and associated attributes belonging to the database.

In fact, the user can select the extensions, previously translated into couples attribute $=$ value , from the graphical user interface of the flexible multicriteria querying system as displayed in Figure 13.

\begin{tabular}{|c|c|c|c|c|c|c|}
\hline \multicolumn{4}{|c|}{ Preferences associated with criteria } & \multicolumn{3}{|l|}{ Argumentation extensions } \\
\hline \multirow[b]{4}{*}{02 permeance } & \multirow{2}{*}{\multicolumn{3}{|c|}{$\checkmark$ allow the ranking of packagings with unknown values for }} & Name & Concept & Value \\
\hline & & & & \multicolumn{3}{|l|}{$\triangleright \square$ Demo } \\
\hline & enlarge min & & $\max$ & $\triangleright$ DemoFrance & & \\
\hline & $9.881786 \mathrm{e}-12$ & $1.270515 \mathrm{e}-11$ & $1.552852 \mathrm{e}-11$ & \multicolumn{3}{|l|}{$\triangle$ Example 1} \\
\hline $\mathrm{CO} 2$ permeance & $9.064443 e-11$ & $1.165428 \mathrm{e}-10$ & $1.424412 \mathrm{e}-10$ & \multicolumn{3}{|l|}{$\Delta \square$ End Of Life } \\
\hline Temperature & 14 & 18 & 22 & \multicolumn{3}{|l|}{$\Delta \sqrt{31}$} \\
\hline Biodegradability & \multicolumn{3}{|l|}{$\nabla$} & Biodegradability & BiodegradablePackaging & true \\
\hline \multirow[t]{3}{*}{ Transparency } & \multirow{3}{*}{\multicolumn{2}{|c|}{$\begin{array}{l}\text { transparent } \\
\text { translucent } \\
\text { opaque }\end{array}$}} & & $D 32$ & & \\
\hline & & & & $\triangleright \square$ Shelf life & & \\
\hline & & & & \multicolumn{3}{|c|}{ 1 $\square$ III , } \\
\hline argumentation & \multicolumn{3}{|c|}{ rank packagings } & \multicolumn{3}{|c|}{ add } \\
\hline
\end{tabular}

Figure 13: Selecting preferences associated with the end of life viewpoint to complete the query with Biodegradable $=$ True. (File 31 corresponds to Extension 1 in Figure 12). 
Figure 14 finally displays the final result after execution of the multicriteria querying which takes into account the consensual preferences about the biodegradability attribute. Four packagings are ranked according to their relevance to the query preferences.

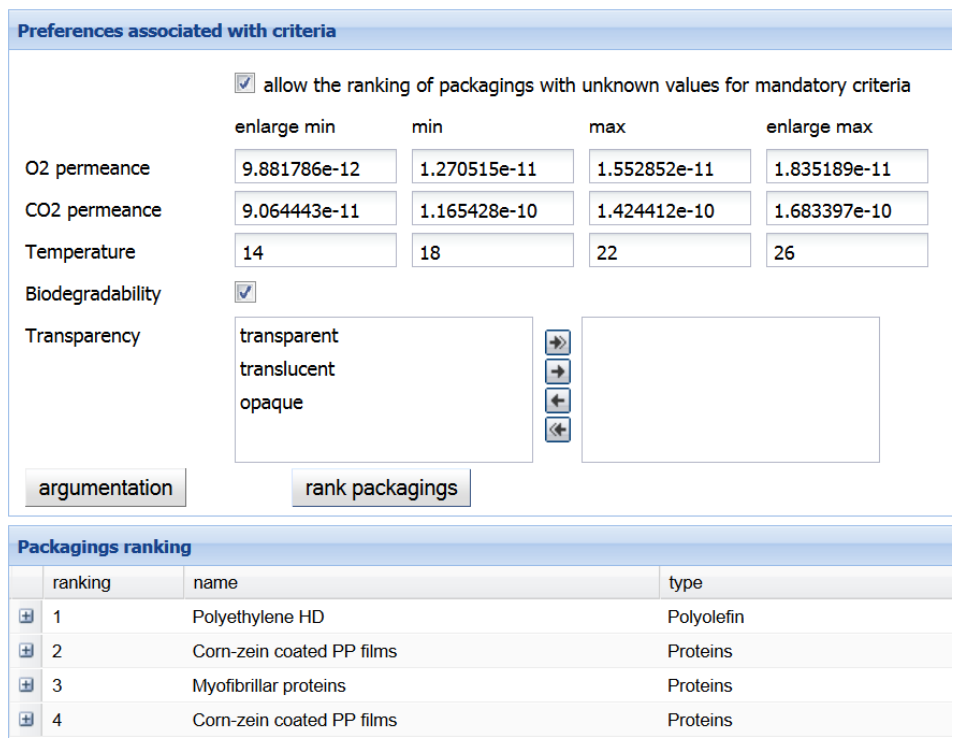

Figure 14: The final result after running the multi-criteria querying process.

\subsection{Evaluation of the argumentation tool}

The evaluation of the tool has been carried out in two phases. The first one was performed at the middle of the implementation process when only main user interfaces and functions were implemented. The second phase was performed at the end of the implementation process.

The first evaluation aimed at validating the user interfaces and the usability of the tool. The evaluation method was based on the implementation 
of real use cases in which some experts involved in the project were invited to express some text arguments. Then, we guided them through the argumentation process, from argument formalization to extension computation. The main evaluation criteria considered here were:

- The intuitiveness of the user interfaces,

- The relevance of the functions implemented,

- The usefulness of the graphical representation of the data (argument graph made of arguments and attacks, argument derivation, alternatives and rules representation), The conclusions drawn from this early evaluation is as follows.

- The experts (who are not computer scientists) were more interested on the input and the output of the tool than on the detailed process it goes through. Thus, argument modeling and extension outputs are the main functions of the tool from the experts' standpoint.

Consequently, we have hided by default the graphical representation of the arguments, attacks amongst them and the argument derivation process so as the information shown to the users focus on the text argument, the result of modeling and the output of extensions. The users can still display on demand further details about the argumentation process. 
- The second feedback was about the rule modeling as either defeasible or strict, which is seen by the experts as an important limitation of the expressiveness of arguments, since a rule could be less/more defeasible than another. As mentioned on future work, this issue gave birth to fuzzy argumentation framework [Tamani and Croitoru, 2014b, Tamani and Croitoru, 2014a].

The second evaluation process aimed at validating the reasoning process by the experts. During a 2-day workshop, we have collected text arguments on diverse options about the end of life of packaging in different European countries. We have modeled the arguments and compute the extensions, which we have after that shown to the experts the second day to evaluate the likelihood and the coherence of the results obtained. The evaluation criterion considered here is the correctness of the implementation of the reasoning process.

The evaluation of the argumentation tool has been carried out for the following four countries: France, Hungary, Italy and Sweden. We summarize in Table 1 the data collected via discussions and interviews with diverse experts from each country about the aspect packaging's "end of life". For each country, we listed the discussed options according to the local context and the number of text arguments collected. We refer the reader to Tables $3,4,5$ and 6 in appendix A for the text arguments gathered for France, Hungary, Italy and Sweden, respectively.

Table 2 summarizes the results obtained for each country in terms of 
Table 1: Options discussed within the arguments collected for each country.

\begin{tabular}{|c|c|c|}
\hline Country & $\begin{array}{c}\text { Options discussed for end of life } \\
\text { viewpoint }\end{array}$ & $\begin{array}{l}\text { Number of } \\
\text { text } \\
\text { arguments }\end{array}$ \\
\hline Hungary & $\begin{array}{c}\text { Biodegradable Packaging } \\
\text { Compostable Packaging } \\
\text { Recyclable Packaging }\end{array}$ & 9 \\
\hline Italy & $\begin{array}{c}\text { Biodegradable Packaging } \\
\text { Compostable Packaging } \\
\text { Recyclable Packaging }\end{array}$ & 8 \\
\hline Sweden & $\begin{array}{c}\text { Biodegradable Packaging } \\
\text { Compostable Packaging } \\
\text { Incinerated Packaging } \\
\text { Landfill Packaging } \\
\text { Recyclable Packaging }\end{array}$ & 13 \\
\hline France & $\begin{array}{c}\text { Biodegradable Packaging } \\
\text { Burying Packaging } \\
\text { Compostable Packaging } \\
\text { MultiLayered Recyclable Packaging } \\
\text { Recyclable Packaging } \\
\text { Other (Incinerated) Packaging }\end{array}$ & 25 \\
\hline
\end{tabular}


the number of logical arguments, number of conflicts, number of preferred extensions ${ }^{4}$ returned and the skeptical output of the argumentation system. The skeptical output contains the consensual options (displayed in bold font) which are supported by arguments present in any extension, in addition to other concepts corresponding to reasons why these options are delivered.

In the case of Hungary, the argumentation tool returns two preferred extensions and two skeptically accepted choices, namely: Biodegradable and Not Recyclable packaging. The argumentation tool recommends biodegradable packaging because they have a positive image regarding the protection of the environment, which increases their marketing attractiveness. The recyclable packaging are discarded cause of the extra taxes imposed by the local authorities.

In the case of Italy, the argumentation tool returns the same skeptical outputs as for Hungary and for quite similar reasons. Biodegradable packaging are returned for their positive image toward the protection of the environment, but marketing aspects are not important for Italy. Recyclable packaging are discarded because of the taxes the consumers would have to pay.

In the case of Sweden, the argumentation tool returns two preferred extensions and three skeptically accepted choices: Biodegradable, Incinerated

\footnotetext{
${ }^{4}$ We computed for each country the extensions under diverse semantics (admissible, preferred, stable, semi-stable, ground, etc.), but we limit our analysis to the preferred semantics since it delivers the largest sets of non-conflicting arguments that defend themselves against attacks.
} 
Table 2: Obtained results for each country.

\begin{tabular}{|c|c|c|c|c|}
\hline Country & $\begin{array}{c}\text { Number } \\
\text { of logical } \\
\text { argu- } \\
\text { ments }\end{array}$ & $\begin{array}{l}\text { Number } \\
\text { of Con- } \\
\text { flicts }\end{array}$ & $\begin{array}{c}\text { Number } \\
\text { of } \\
\text { preferred } \\
\text { exten- } \\
\text { sions } \\
\end{array}$ & $\begin{array}{c}\text { Number of skeptical } \\
\text { outputs }\end{array}$ \\
\hline Hungary & 50 & 316 & 2 & $\begin{array}{c}\text { Biodegradable Packaging } \\
\text { Not Recyclable Packaging } \\
\text { Marketing Attractive } \\
\text { Packaging } \\
\text { Not HighTaxes } \\
\text { Protect Env Packaging }\end{array}$ \\
\hline Italy & 54 & 409 & 2 & $\begin{array}{c}\text { Biodegradable Packaging } \\
\text { Not Recyclable Packaging } \\
\text { Not HighTaxes, } \\
\text { Protect Env. Packaging }\end{array}$ \\
\hline Sweden & 146 & 2445 & 2 & $\begin{array}{l}\text { Biodegradable Packaging } \\
\text { Incinerated Packaging } \\
\text { Not Landfill Packaging } \\
\text { Energy Recovery Packaging } \\
\text { Gas Production Packaging } \\
\text { Protect Env. Packaging }\end{array}$ \\
\hline France & 117 & 4408 & 2 & $\begin{array}{c}\text { Not MultiLayered } \\
\text { Recyclable Packaging } \\
\text { OtherPack (incinerated) } \\
\text { BonusTax Packaging } \\
\text { Energy Production Packaging } \\
\text { High Env. Impact Packaging } \\
\text { HighTreatmentCost } \\
\text { Low Env. Impact Packaging } \\
\text { Not Malus Tax } \\
\text { Not NoChain } \\
\text { Not Recycling Disturb sorting } \\
\text { Not Visual Pollution } \\
\text { Partially Recycled Packaging }\end{array}$ \\
\hline
\end{tabular}


and Not Landfill packaging. The main reasons here to accept biodegradable packaging are energy bio-gas production in addition to the environment protection. Incinerated packaging are also accepted since they are used to produce energy. The landfill packaging are rejected in all situations because the authorities forbid all kinds of landfilling solution for packaging.

In the case of France, due to the number of arguments and conflicts generated $^{5}$, the computation of extensions takes a long time and the server ran out of resources (because of the Java DungAF which implements exponential algorithms as shown in [Vreeswijk, 2006]). Therefore, we simplified the argumentation graph by deleting the rules leading to self-attacked arguments. The result delivered from the argumentation tool is actually an approximation. From the returned two preferred extensions, two skeptically accepted choices are obtained, namely: Not MultiLayered recyclable Packaging and incinerated Packaging (also denoted by OtherPack). The incinerated packaging produce energy and the multilayered recyclable packaging are rejected since there is no recycling chain available. The rest of listed reasons are related to the other discarded options (biodegradable, compostable, recyclable and burying packaging). There have been returned by the system because of the simplification of the argumentation graph.

These results are however validated by the experts with respect to the text arguments used in the computation of extensions.

To conclude this section, we have learned from this evaluation that:

\footnotetext{
${ }^{5}$ The original argument graph contains 289 logical arguments and 27113 conflicts.
} 
- The argumentation process delivered coherent results, in the sense of attack definition,

- The process can be time consuming when the number of text arguments is important,

- The need for an explanation function when the output contains some unexpected results, or in the contrary does not contain some expected results.

\section{Related work}

Related work can be considered according to application standpoints in the argumentation field. Based on the recent survey [Schneider et al., 2013] and the web site http://www.phil.cmu.edu/projects/argument_mapping/, applications and tools developed for argumentation can be divided into the two following categories:

- Software for argument expression and modeling. This software, such as Araucaria [Reed and Rowe, 2004], Argunet [Schneider et al., 2007] and DebateGraph, ${ }^{6}$ allows the expression of arguments as texts to manually formalize them as hypothesis and conclusions. The user can after that save the arguments as an XML file.

\footnotetext{
${ }^{6}$ www.debategraph.org
} 
- Software for extension computation (we recall that an extension is a conflict-free subset of arguments defending themselves against attacks) over an argumentation graph given as input, like OVA-GEN ${ }^{7}$ and Ar$\mathrm{guLab}^{8}$.

Despite the plethora of available software in the field of argumentation, there are few argumentation software systems implementing an argumentation process from argument expression to extensions computation, while providing users with several graphical user interfaces to visualize the entire process. In addition to the software introduced in this paper we can cite ArgTrust [Parsons et al., 2013], in which the authors considered the uncertainty underlying the sources of the knowledge used in the argumentation framework for decision making; CISpaces framework [Toniolo et al., 2014], which supports collaborative intelligence analysis of conflicting information in collaboration exploiting argumentation schemes; "Quaestion-it.com" [Evripidou and Toni, 2014] which is a social intelligence debating platform, based on computational argumentation, for modeling and analyzing social discussions, and demonstrate a question-and-answer web application providing support for extracting intelligent answers to user-posed questions; and the Carneades argumentation system web version [Gordon, 2013], which provides software tools based on a common computational model of argument graphs useful for policy deliberations.

\footnotetext{
${ }^{7}$ http://ova.computing.dundee.ac.uk/ova-gen/

${ }^{8}$ https://code.google.com/p/pyafl/
} 
We presented in this paper a real world application based on argumentation reasoning and connected to the querying process by harnessing the result of the argumentation process as justified preferences expressing consensual solutions encompassing the stakeholders needs and requirements. It is to the best of our knowledge an original contribution in the field of food packaging.

\section{Conclusion and Future Work}

In this paper we applied an argumentation approach to a real use case from the industry, based on an ASPIC argumentation system specifications allowing stakeholders to express their preferences and providing the system with stable concepts and inference rules of a domain. We have proposed an argumentation system in which each criterion (attribute or aspect) is considered as a viewpoint in which stakeholders express their arguments in homogeneous way. Each viewpoint delivers extensions supporting or opposing certain choices according to one packaging aspect, which are then used in the querying process. The approach was implemented as a web-based application and evaluated in real use cases modeling possible packaging end of life solutions in four european countries.

Compared to the current stakeholder decision-making practices, this DSS is a significant breakthrough in the field of food packaging. The DSS proposed in this paper answers to multi-criteria queries including several food packaging characteristics. Moreover, the DSS is able to aggregate in a consensual 
way the arguments expressed by to the packaging food chain stakeholders about their constraints, acceptances and needs considering several criteria (biodegradability, transparency etc). To the best of our knowledge, this type of tool was never attempted previously in that field. Among the list of possible packagings retrieved by the DSS, the user has to choose one (usually the one ranked on top) and then to test it in real condition of use. Compared to the empirical approach that requires numerous experimental trials, using the DSS the user will have only one trial to perform (validation step). For the aforementioned reasons, the DSS proposed in this paper can be of help for decision-making in the field of food packaging for fresh produce.

As future work, we need to improve the scalability of the argumentation system regarding the number of arguments expressed within a viewpoint. This issue could be tackled either by considering recently introduced effective approaches and algorithms for computation, such as SATbased approach [Cerutti et al., 2014a, Cerutti et al., 2014b], recursive metaalgorithm [Cerutti et al., 2014c], and algorithms for decision problems [Nofal et al., 2014]. Another possible solution could be splitting again arguments' viewpoint into subtopics which would be easier to handle as small subsets of arguments. This solution imposes to study how to aggregate the solutions delivered by subtopics to compute the final recommendation of a given viewpoint.

The approach proposed and implemented in this paper can benefit from the diverse argumentation approaches for decision making, such as the value- 
based argumentation approaches [Atkinson and Bench-Capon, 2007]

[Bench-Capon et al., 2011, Bench-Capon et al., 2013, Prakken, 2012] which argument schemes are used as means to deliberate or to reason with legal cases using values. Besides, it is also possible to refine the reasoning with preferences which can be expressed over the arguments or the alternatives like in [Amgoud and Prade, 2009, Modgil and Prakken, 2013, van der Weide et al., 2011] or by multi-criteria argument selection such as in [van der Weide et al., 2012].

Besides, some experts feedback pointed out the difficulties to consider a rule as either strict or defeasible and expressed the need to be able to specify a sort of importance encompassing the notions of strictness and defeasibility. One work in progress [Tamani and Croitoru, 2014b, Tamani and Croitoru, 2014a] is to extend the proposed approach to fuzziness to make it possible to deal with vague and uncertain concepts and rules. Another important feedback from the expert was about explaining the results delivered from the argumentation process. The experts expressed the need for explanation function which is capable to provide more information about how a given conclusion was or was not delivered. The issue of explaining is currently undertaken and some preliminary results have already published such as [Arioua et al., 2014a] in which the authors introduced a preliminary approach to explain why a result was delivered, and [Arioua et al., 2014b] in which the authors proposed a dialogical approach to explain why a given conclusion was not delivered by the argumentation process.

Another line to develop consists of studying the bipolarity in our con- 
text of argumentation, since extensions can be formed to support/oppose decisions. Therefore a bipolar reasoning process could be considered as a refinement of the introduced argument-based reasoning process, especially when a single choice is accepted by some viewpoints and rejected by others.

\section{Acknowledgements}

The research leading to these results has received funding from the European Community's Seventh Framework Program (FP7/ 2007-2013) under the grant agreement $n^{\circ} \mathrm{FP} 7-265669-E c o B i o C A P$ project.

\section{References}

[Amgoud et al., 2006] Amgoud, L., Bodenstaff, L., Caminada, M., McBurney, P., Parsons, S., Prakken, H., Veenen, J., and Vreeswijk, G. (2006). Final review and report on formal argumentation system.deliverable d2.6 aspic. Technical report.

[Amgoud and Prade, 2009] Amgoud, L. and Prade, H. (2009). Using arguments for making and explaining decisions. Artificial Intelligence, 173(34):413-436.

[Arioua et al., 2014a] Arioua, A., Tamani, N., and Croitoru, M. (2014a). On conceptual graphs and explanation of query answering under inconsistency. 
In Graph-Based Representation and Reasoning - 21st International Conference on Conceptual Structures, ICCS 2014, Iaşi, Romania, July 27-30, 2014, Proceedings, pages 51-64.

[Arioua et al., 2014b] Arioua, A., Tamani, N., Croitoru, M., and Buche, P. (2014b). Query failure explanation in inconsistent knowledge bases: A dialogical approach. In Bramer, M. and Petridis, M., editors, Research and Development in Intelligent Systems XXXI, pages 119-133. Springer International Publishing.

[Atkinson and Bench-Capon, 2007] Atkinson, K. and Bench-Capon, T. (2007). Practical reasoning as presumptive argumentation using action based alternating transition systems. Artificial Intelligence, 171(1015):855-874. Argumentation in Artificial Intelligence.

[Baroni et al., 2011] Baroni, P., Caminada, M., and Giacomin, M. (2011). An introduction to argumentation semantics. The Knowledge Engineering Review, 26(04):365-410.

[Bench-Capon et al., 2011] Bench-Capon, T., Prakken, H., and Visser, W. (2011). Argument schemes for two-phase democratic deliberation. In Proceedings of the 13th International Conference on Artificial Intelligence and Law, ICAIL '11, pages 21-30, New York, NY, USA. ACM.

[Bench-Capon et al., 2013] Bench-Capon, T., Prakken, H., Wyner, A., and Atkinson, K. (2013). Argument schemes for reasoning with legal cases 
using values. In Proceedings of the Fourteenth International Conference on Artificial Intelligence and Law, ICAIL '13, pages 13-22, New York, NY, USA. ACM.

[Besnard and Hunter, 2008] Besnard, P. and Hunter, A. (2008). Elements of Argumentation. The MIT Press.

[Bondarenko et al., 1997] Bondarenko, A., Dung, P. M., Kowalski, R. A., and Toni, F. (1997). An abstract, argumentation-theoretic approach to default reasoning. Artificial intelligence, 93(1):63-101.

[Bouyssou et al., 2009] Bouyssou, D., Dubois, D., Pirlot, M., and Prade, H. (2009). Decision-making process - Concepts and Methods. Wiley.

[Caminada and Amgoud, 2007] Caminada, M. and Amgoud, L. (2007). On the evaluation of argumentation formalisms. Artificial Intelligence, $171: 286-310$.

[Caminada et al., 2011] Caminada, M. W., Carnielli, W. A., and Dunne, P. E. (2011). Semi-stable semantics. Journal of Logic and Computation, page exr033.

[Cerutti et al., 2014a] Cerutti, F., Giacomin, M., and Vallati, M. (2014a). Argsemsat: Solving argumentation problems using SAT. In [Parsons et al., 2014], pages 455-456.

[Cerutti et al., 2014b] Cerutti, F., Giacomin, M., Vallati, M., and Zanella, M. (2014b). A scc recursive meta-algorithm for computing preferred la- 
bellings in abstract argumentation. In 14th International Conference on Principles of Knowledge Representation and Reasoning (KR).

[Cerutti et al., 2014c] Cerutti, F., Giacomin, M., Vallati, M., and Zanella, M. (2014c). An SCC recursive meta-algorithm for computing preferred labellings in abstract argumentation. In Baral, C., Giacomo, G. D., and Eiter, T., editors, Principles of Knowledge Representation and Reasoning: Proceedings of the Fourteenth International Conference, KR 2014, Vienna, Austria, July 20-24, 2014. AAAI Press.

[Coste-Marquis et al., 2005] Coste-Marquis, S., Devred, C., and Marquis, P. (2005). Symmetric argumentation frameworks. In Godo, L., editor, Symbolic and Quantitative Approaches to Reasoning with Uncertainty, volume 3571 of Lecture Notes in Computer Science, pages 317-328. Springer Berlin Heidelberg.

[Destercke et al., 2011] Destercke, S., Buche, P., and Guillard, V. (2011). A flexible bipolar querying approach with imprecise data and guaranteed results. Fuzzy sets and Systems, 169:51-64.

[Dung, 1995] Dung, P. M. (1995). On the acceptability of arguments and its fundamental role in nonmonotonic reasoning, logic programming and n-persons games. Artificial Intelligence, 77(2):321-357. 
[Evripidou and Toni, 2014] Evripidou, V. and Toni, F. (2014). Quaestioit.com: a social intelligent debating platform. Journal of Decision Systems, 23(3):333-349.

[Gordon, 2013] Gordon, T. F. (2013). Introducing the carneades web application. In Proceedings of the Fourteenth International Conference on Artificial Intelligence and Law, ICAIL '13, pages 243-244, New York, NY, USA. ACM.

[Guillard et al., 2012] Guillard, V., Guillaume, C., and Destercke, S. (2012). Parameters uncertainties and error propagation in the modelling of modified atmosphere packaging. Postharvest Biology and technologies, 67:154166.

[Modgil and Prakken, 2013] Modgil, S. and Prakken, H. (2013). A general account of argumentation with preferences. Artificial Intelligence, 195:361397.

[Nofal et al., 2014] Nofal, S., Atkinson, K., and Dunne, P. E. (2014). Algorithms for decision problems in argument systems under preferred semantics. Artif. Intell., 207:23-51.

[Parsons et al., 2014] Parsons, S., Oren, N., Reed, C., and Cerutti, F., editors (2014). Computational Models of Argument-Proceedings of COMMA 2014, Atholl Palace Hotel, Scottish Highlands, UK, September 9-12, 2014, 
volume 266 of Frontiers in Artificial Intelligence and Applications. IOS Press.

[Parsons et al., 2013] Parsons, S., Sklar, E., Salvit, J., Wall, H., and Li, Z. (2013). Argtrust: Decision making with information from sources of varying trustworthiness. In Proceedings of the 2013 International Conference on Autonomous Agents and Multi-agent Systems, AAMAS '13, pages 1395-1396, Richland, SC. International Foundation for Autonomous Agents and Multiagent Systems.

[Prakken, 2010] Prakken, H. (2010). An abstract framework for argumentation with structured arguments. Argument and Computation, 1(2):93-124.

[Prakken, 2012] Prakken, H. (2012). Formalising a legal opinion on a legislative proposal in the aspic + framework. In Legal Knowledge and Information Systems: JURIX 2012: The Twenty-Fifth Annual Conference, volume 250, page 119. IOS Press.

[Rahwan and Simari, 2009] Rahwan, I. and Simari, G. R. (2009). Argumentation in Artificial Intelligence. Springer Publishing Company, Incorporated, 1st edition.

[Reed and Rowe, 2004] Reed, C. and Rowe, G. (2004). Araucaria: Software for argument analysis, diagramming and representation. International Journal on Artificial Intelligence Tools, 13(04):961-979. 
[Schneider et al., 2007] Schneider, D. C., Voigt, C., and Betz, G. (2007). Argunet- a software tool for collaborative argumentation analysis and research. In 7th Workshop on Computational Models of Natural Argument (CMNA VII).

[Schneider et al., 2013] Schneider, J., Groza, T., and Passant, A. (2013). A review of argumentation for the social semantic web. Semantic Web, $4(2): 159-218$.

[Tamani and Croitoru, 2014a] Tamani, N. and Croitoru, M. (2014a). Fuzzy argumentation system for decision support. In Laurent, A., Strauss, O., Bouchon-Meunier, B., and Yager, R. R., editors, Information Processing and Management of Uncertainty in Knowledge-Based Systems - 15th International Conference, IPMU 2014, Montpellier, France, July 15-19, 2014, Proceedings, Part I, volume 442 of Communications in Computer and Information Science, pages 77-86. Springer.

[Tamani and Croitoru, 2014b] Tamani, N. and Croitoru, M. (2014b). A quantitative preference-based structured argumentation system for decision support. In IEEE International Conference on Fuzzy Systems, FUZZIEEE 2014, Beijing, China, July 6-11, 2014, pages 1408-1415. IEEE.

[Tamani et al., 2013] Tamani, N., Croitoru, M., and Buche, P. (2013). A viewpoint approach to structured argumentation. In Bramer, M. and Petridis, M., editors, The Thirty-third SGAI International Conference on 
Innovative Techniques and Applications of Artificial Intelligence, pages 265-271.

[Tamani et al., 2014] Tamani, N., Croitoru, M., and Buche, P. (2014). Conflicting viewpoint relational database querying: an argumentation approach. In Scerri, L. and Huhns, B., editors, Proceedings of the 13th International Conference on Autonomous Agents and Multiagent Systems (AAMAS 2014), pages 1553-1554.

[Toniolo et al., 2014] Toniolo, A., Dropps, T., Ouyang, W. R., Allen, J. A., Norman, T. J., Oren, N., Srivastava, M. B., and Sullivan, P. (2014). Argumentation-based collaborative intelligence analysis in cispaces. In [Parsons et al., 2014], pages 481-482.

[van der Weide et al., 2011] van der Weide, T., Dignum, F., Meyer, J.-J., Prakken, H., and Vreeswijk, G. (2011). Arguing about preferences and decisions. In McBurney, P., Rahwan, I., and Parsons, S., editors, Argumentation in Multi-Agent Systems, volume 6614 of Lecture Notes in Computer Science, pages 68-85. Springer Berlin Heidelberg.

[van der Weide et al., 2012] van der Weide, T., Dignum, F., Meyer, J.-J., Prakken, H., and Vreeswijk, G. (2012). Multi-criteria argument selection in persuasion dialogues. In McBurney, P., Parsons, S., and Rahwan, I., editors, Argumentation in Multi-Agent Systems, volume 7543 of Lecture Notes in Computer Science, pages 136-153. Springer Berlin Heidelberg. 
${ }_{1047}$ [Vreeswijk, 2006] Vreeswijk, G. (2006). An algorithm to compute minimally 1048 grounded and admissible defence sets in argument systems. In Dunne, 1049 P. E. and Bench-Capon, T. J. M., editors, Computational Models of Ar1050 gument: Proceedings of COMMA 2006, September 11-12, 2006, Liverpool, ${ }_{1051} U K$, volume 144 of Frontiers in Artificial Intelligence and Applications, 1052 pages $109-120$. IOS Press.

${ }_{1053}[\mathrm{Wu}, 2012] \mathrm{Wu}, \mathrm{Y} .(2012)$. Between argument and conclusion. Argument1054 based approaches to discussion. Inference and Uncertainty. PhD thesis, $1055 \quad$ Université du Luxembourg. 
Table 3: Text Arguments collected for France.

\begin{tabular}{|c|c|}
\hline Stakeholder & Argument \\
\hline Consumer & $\begin{array}{l}\text { Consumers are in favour of biodegradable material because they help } \\
\text { to protect the environment. }\end{array}$ \\
\hline Consumer & $\begin{array}{l}\text { Consumers are in favour of compostable material because they help to } \\
\text { protect the environment. }\end{array}$ \\
\hline Consumer & $\begin{array}{l}\text { Consumers are not in favour of recyclable packaging because associated } \\
\text { taxes are too high. }\end{array}$ \\
\hline Consumer & $\begin{array}{l}\text { Concerning other pack (incineration), consumers express concerns } \\
\text { because of dioxin production which has an impact on human health. }\end{array}$ \\
\hline Expert & $\begin{array}{l}\text { Packaging solutions with low environmental impact (in favour } \\
\text { biodegradable - compostable but also in favour of recycling because } \\
\text { recycling limits environmental impact according to LCA criteria. }\end{array}$ \\
\hline Expert & $\begin{array}{l}\text { LCA results are not in favour of biodegradable materials (recycling of } \\
\text { the matter is favoured). }\end{array}$ \\
\hline Expert & Compostable materials produce high environmental impact. \\
\hline Expert & In France, recyclable materials benefit from eco-tax bonus. \\
\hline Expert & A European directive forbids burying in the horizon of 2020 . \\
\hline Expert & $\begin{array}{l}\text { Compostable material has no value if there is no chain of collection, } \\
\text { sorting and industrial composting. }\end{array}$ \\
\hline Expert & $\begin{array}{l}\text { In France, only PET and PE made bottles and cans containers are } \\
\text { actually recycled. Other types of containers are not recyclable. }\end{array}$ \\
\hline Industry & No recycling chain for multi-layered packaging is available. \\
\hline Researcher & $\begin{array}{l}\text { Biodegradable materials could encourage people to throw their } \\
\text { packaging in nature, causing visual pollution. }\end{array}$ \\
\hline Researcher & Compostable materials produce visual pollution. \\
\hline Researcher & $\begin{array}{l}\text { In France, burying (landfill) is encouraged (because of low cost) } \\
\text { therefore it won't last because it is not sustainable. }\end{array}$ \\
\hline Researcher & $\begin{array}{l}\text { Visual pollution of packaging could not be the worst effect. Knowledge } \\
\text { on the toxicity impact of micro and nanoparticles of partially degraded } \\
\text { plastic is needed (potentially negative impact on health if high } \\
\text { concentration of nanoparticles). }\end{array}$ \\
\hline Researcher & The use of PLA leads to a penalty on eco-tax Eco-Packaging. \\
\hline Researcher & $\begin{array}{l}\text { The bio-polyesters (compostable) as PLA are disturbing of PET } \\
\text { recycling (non-organic polyester). }\end{array}$ \\
\hline
\end{tabular}




\begin{tabular}{|c|c|}
\hline $\begin{array}{c}\text { Waste } \\
\text { Management }\end{array}$ & $\begin{array}{l}\text { In France, numerous waste management facilities are available } \\
\text { (incineration, burying, composting organic waste, methane production } \\
\text { or Anaerobic digestion) which encourages biodegradable materials. }\end{array}$ \\
\hline $\begin{array}{c}\text { Waste } \\
\text { Management }\end{array}$ & $\begin{array}{l}\text { In France, numerous waste management facilities are available } \\
\text { (incineration, burying, composting organic waste, methane production } \\
\text { or Anaerobic digestion) which encourages compostable materials. }\end{array}$ \\
\hline $\begin{array}{c}\text { Waste } \\
\text { Management }\end{array}$ & $\begin{array}{l}\text { Biodegradable materials may disturb the sorting of recyclable } \\
\text { packagings. For example PLA material disturbs the PET recycling. }\end{array}$ \\
\hline $\begin{array}{c}\text { Waste } \\
\text { Management }\end{array}$ & $\begin{array}{l}\text { Compostable materials may disturb the sorting of recyclable } \\
\text { packagings. For example PLA material disturbs the PET recycling. }\end{array}$ \\
\hline $\begin{array}{c}\text { Waste } \\
\text { Management }\end{array}$ & In France, burying is encouraged (low cost around 80 euros per ton). \\
\hline $\begin{array}{c}\text { Waste } \\
\text { Management }\end{array}$ & $\begin{array}{l}\text { In France, Composting is not encouraged (high treatment cost around } \\
130 \text { euros per ton). }\end{array}$ \\
\hline $\begin{array}{c}\text { Waste } \\
\text { Management }\end{array}$ & Incineration (other pack) permits to produce energy. \\
\hline
\end{tabular}

\section{A Lists of text arguments collected and frag-} ments of the obtained formal arguments for

\section{each country}

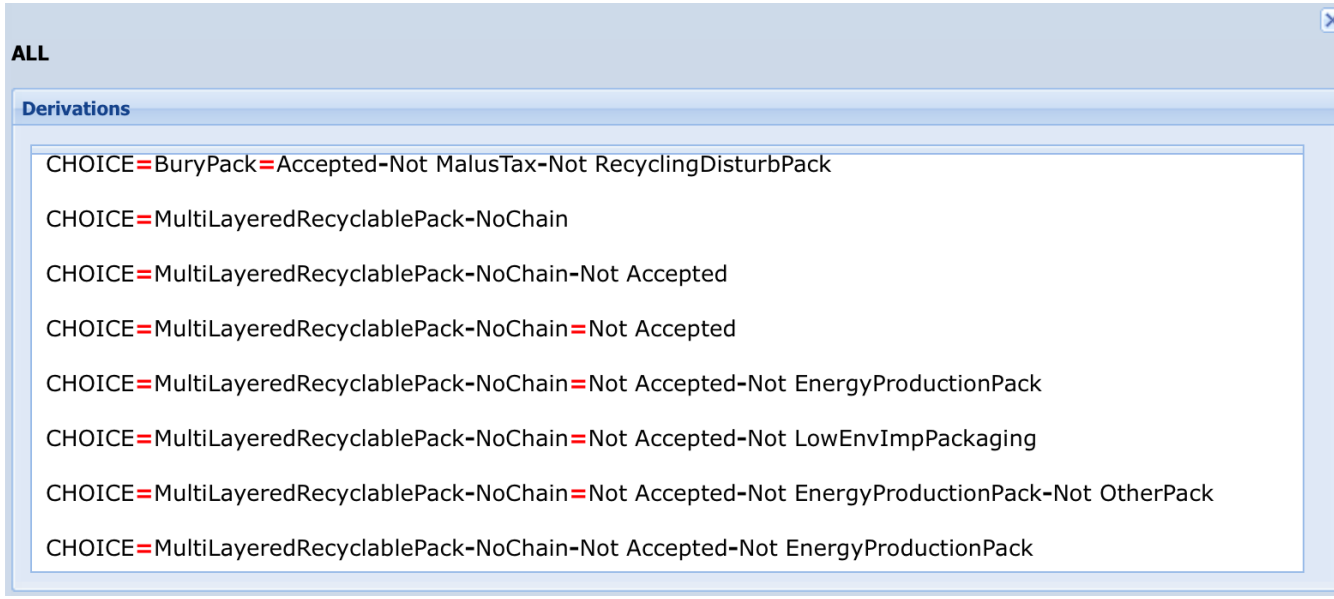

Figure 15: A fragment of formalized rules and obtained attacks in the case of France (approximated model). 
Table 4: Text Arguments collected for Hungary.

\begin{tabular}{|c|l|}
\hline Stakeholder & \multicolumn{1}{c|}{ Argument } \\
\hline \hline Consumer & $\begin{array}{l}\text { Consumers are in favour of biodegradable material because they help } \\
\text { to protect the environment. }\end{array}$ \\
\hline Consumer & $\begin{array}{l}\text { Consumers are in favour of compostable material because they help to } \\
\text { protect the environment. }\end{array}$ \\
\hline Consumer & $\begin{array}{l}\text { Consumers are not in favour of recyclable packaging because associated } \\
\text { taxes are too high. }\end{array}$ \\
\hline Expert & $\begin{array}{l}\text { Packaging solutions with low environmental impact (in favour } \\
\text { biodegradable - compostable but also in favour of recycling because } \\
\text { recycling limits environmental impact according to LCA criteria). }\end{array}$ \\
\hline Expert & $\begin{array}{l}\text { LCA results are not in favour of biodegradable materials (recycling is } \\
\text { favoured). }\end{array}$ \\
\hline Expert & Compostable materials produce high environmental impact. \\
\hline Expert & $\begin{array}{l}\text { Biodegradable packaging are not well familiarized by the food } \\
\text { manufacturer (until now only 1-2 suppliers entered into the Hungarian } \\
\text { market), but in the closely future, the companies would like to use the } \\
\text { biodegradable packaging as an effective marketing tool. }\end{array}$ \\
\hline Researcher & $\begin{array}{l}\text { Biodegradable materials could encourage people to throw their } \\
\text { packaging in nature, causing visual pollution. }\end{array}$ \\
\hline Researcher & Compostable materials produce visual pollution. \\
\hline
\end{tabular}

Figures 15, 16, 17 and 18 display fragments of formal arguments derived from the formalized choices and concepts, in the case of France, Hungary, Italy and Sweden respectively. The red symbol "=" connecting concepts means that the rule used is defeasible and the black symbol "-" means that the rule used is formalized as strict. The user can access to this view by clicking on the button "Show Derivations" in the main interface of the tool (see Zone 3 in Figure 4). 


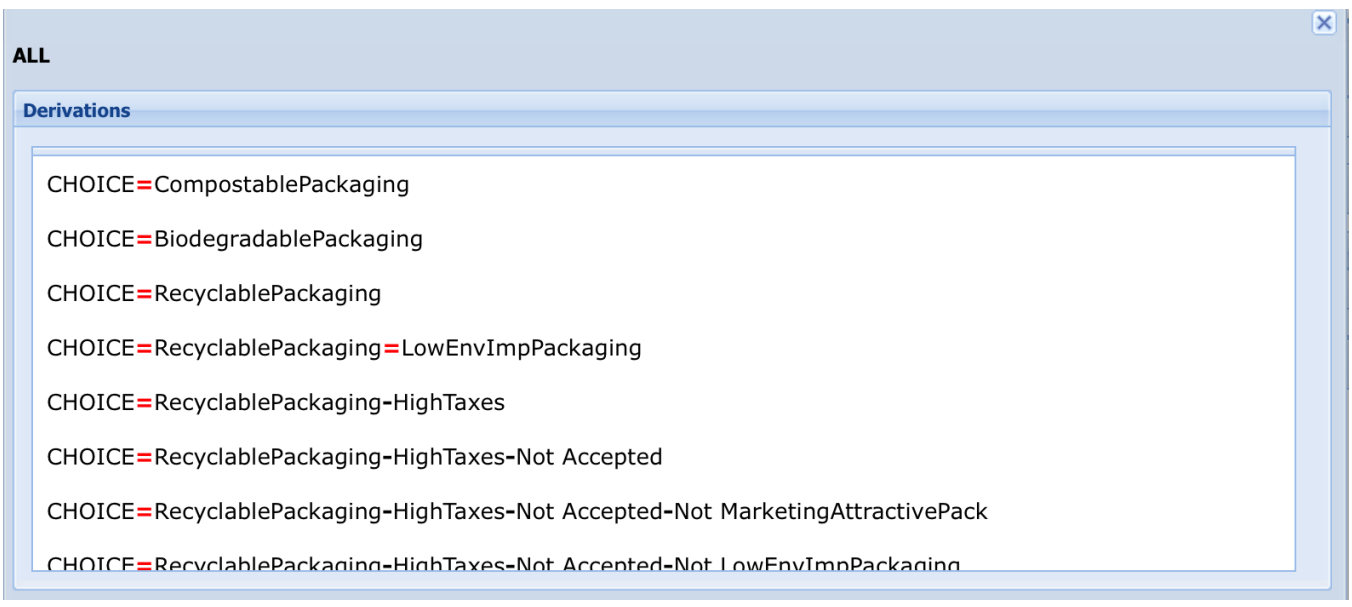

Figure 16: A fragment of formalized rules and obtained attacks in the case of Hungary.

Table 5: Text Arguments collected for Italy.

\begin{tabular}{|c|l|}
\hline Stakeholder & \multicolumn{1}{|c|}{ Argument } \\
\hline \hline Consumer & $\begin{array}{l}\text { Consumers are in favour of biodegradable material because they help } \\
\text { to protect the environment. }\end{array}$ \\
\hline Consumer & $\begin{array}{l}\text { Consumers are in favour of compostable material because they help to } \\
\text { protect the environment. }\end{array}$ \\
\hline Consumer & $\begin{array}{l}\text { Consumers are not in favour of recyclable packaging because associated } \\
\text { taxes are too high. }\end{array}$ \\
\hline Expert & $\begin{array}{l}\text { Packaging solutions with low environmental impact (in favour } \\
\text { biodegradable - compostable but also in favour of recycling because } \\
\text { recycling limits environmental impact according to LCA criteria). }\end{array}$ \\
\hline Expert & $\begin{array}{l}\text { LCA results are not in favour of biodegradable materials (recycling is } \\
\text { favoured). }\end{array}$ \\
\hline Expert & Compostable materials produce high environmental impact. \\
\hline Researcher & $\begin{array}{l}\text { Biodegradable materials could encourage people to throw their } \\
\text { packaging in nature, causing visual pollution. }\end{array}$ \\
\hline Researcher & Compostable materials produce visual pollution. \\
\hline
\end{tabular}




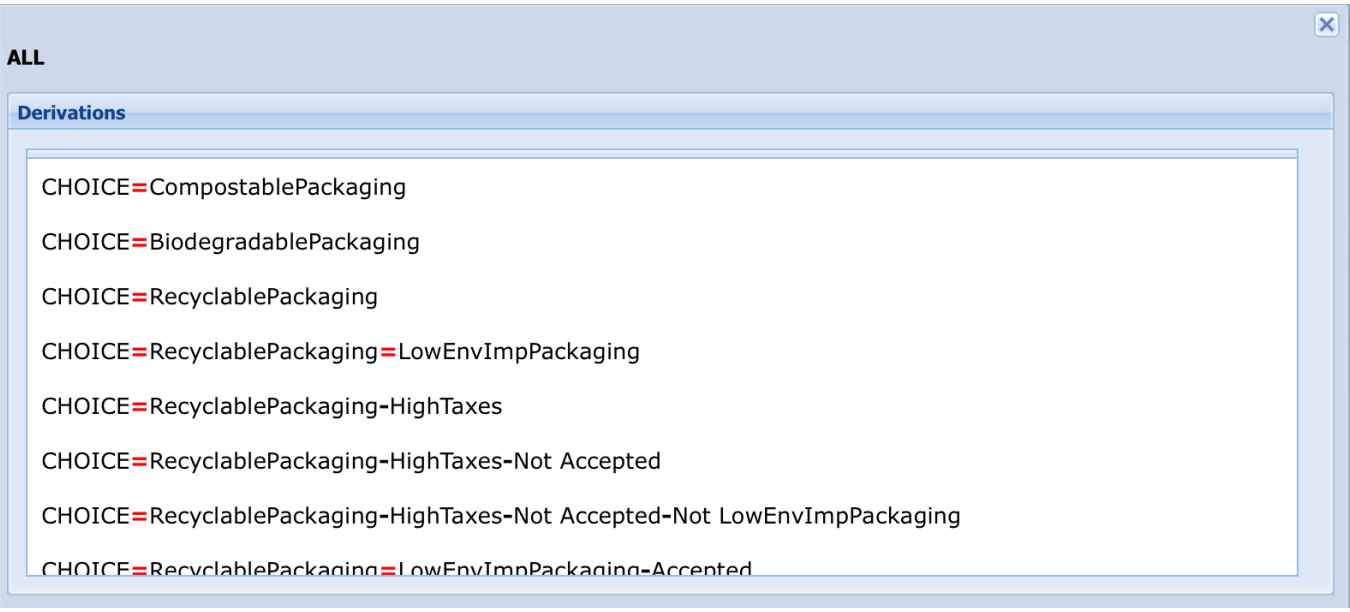

Figure 17: A fragment of formalized rules and obtained attacks in the case of Italy.

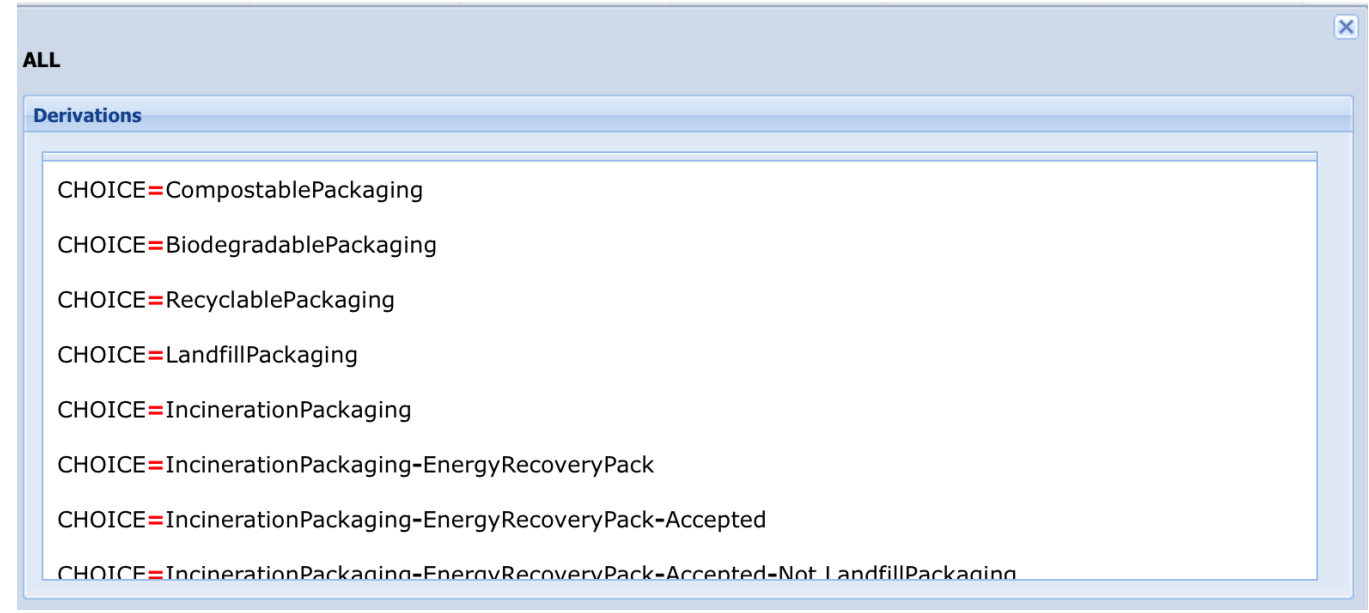

Figure 18: A fragment of formalized rules and obtained attacks in the case of Sweden. 
Table 6: Text Arguments collected for Sweden.

\begin{tabular}{|c|c|}
\hline Stakeholder & Argument \\
\hline Consumer & $\begin{array}{l}\text { Consumers are in favour of biodegradable material because they help } \\
\text { to protect the environment. }\end{array}$ \\
\hline Consumer & $\begin{array}{l}\text { Consumers are in favour of compostable material because they help to } \\
\text { protect the environment. }\end{array}$ \\
\hline Consumer & $\begin{array}{l}\text { Consumers are not in favour of recyclable packaging because associated } \\
\text { taxes are too high. }\end{array}$ \\
\hline Expert & $\begin{array}{l}\text { Packaging solutions with low environmental impact (in favour of } \\
\text { biodegradable - compostable but also in favour of recycling because } \\
\text { recycling limits environmental impact according to LCA criteria). }\end{array}$ \\
\hline Expert & $\begin{array}{l}\text { LCA results are not in favour of biodegradable materials (recycling is } \\
\text { favoured). }\end{array}$ \\
\hline Expert & Compostable materials produce high environmental impact. \\
\hline Expert & Landfill (or any waste) is not allowed. \\
\hline Expert & $\begin{array}{l}\text { Waste incineration with energy recovery is important for many cities in } \\
\text { Sweden (district heat, for heating houses). }\end{array}$ \\
\hline Expert & $\begin{array}{l}\text { For Biodegradable: Anaerobic digestion plants (with organic waste) for } \\
\text { bio-gas production are present and well developed in many Swedish } \\
\text { cities. }\end{array}$ \\
\hline Expert & $\begin{array}{l}\text { For Compostable packaging: Anaerobic digestion plants (with organic } \\
\text { waste) for bio-gas production are present and well developed in many } \\
\text { Swedish cities. }\end{array}$ \\
\hline Researcher & $\begin{array}{l}\text { Biodegradable materials could encourage people to throw their } \\
\text { packaging in nature, causing visual pollution. }\end{array}$ \\
\hline Researcher & Compostable materials produce visual pollution. \\
\hline Researcher & $\begin{array}{l}\text { Food producer and consumer are obliged to put plastic, paper, glass } \\
\text { and aluminum/metal to recycling. }\end{array}$ \\
\hline
\end{tabular}

